\title{
Fashion Brand Purity and Firm Performance
}

\author{
Jin-hui Zheng, ${ }^{1}$ Zixia Cao, ${ }^{2}$ Xin Dai, ${ }^{3}$ and Chun-Hung Chiu ${ }^{3}$ \\ ${ }^{1}$ Institute of Textiles and Clothing, The Hong Kong Polytechnic University, Hung Hom, Kowloon, Hong Kong \\ ${ }^{2}$ Department of Management, Marketing and General Business, West Texas A\&M University, Canyon, TX 79016, USA \\ ${ }^{3}$ Sun Yat-Sen Business School, Sun Yat-Sen University, No. 135, Xingang West Road, Guangzhou 510275, China
}

Correspondence should be addressed to Xin Dai; daixin@mail.sysu.edu.cn

Received 7 December 2012; Accepted 12 February 2013

Academic Editor: Tsan-Ming Choi

Copyright (C) 2013 Jin-hui Zheng et al. This is an open access article distributed under the Creative Commons Attribution License, which permits unrestricted use, distribution, and reproduction in any medium, provided the original work is properly cited.

\begin{abstract}
A large number of prior empirical research and case studies used qualitative methodology to discuss the fashion brand dilution resulting from consumer base extension from the target group(s) to the nontarget groups and its impacts. From a different perspective, this paper establishes a dynamic brand dilution and performance model, demonstrating how dynamic changes of sales volumes involving the two consumer groups affect the degree of brand dilution and the performance of the brand. We incorporate the factor "brand purity" to the model as a quantitative measure of brand dilution level that affects firm annual revenue and profit change comprehensively in iteration. Our model suggests that fashion brands, especially luxury brands, can be easily diluted under the pressure of firm growth, and the brands suffer the significant negative impact on their revenues and profit. While increasing sales volume can aggravate the negative consequences, brand purity can be increased through limiting the consumer base to the target group only.
\end{abstract}

\section{Introduction}

The challenge faced by many fashion brands is that whether to stay within the existing target market to avoid brand dilution or to extend the brand to a larger market with the risks of diluting the brand [1]. Increasing consumer base seems to facilitate firm growth, but prior research found that consumers tend to value the product (or the brand) less when a larger group of consumers owns it [2]. Because consumers' decision to buy a "conspicuous" branded product depends on not only the product's functionality, but also the brand's social benefits such as its prestige [2-6], the fashion brand needs to maintain its exclusivity. A brand is no longer worth its vertiginous price if it is owned by too many consumers [7].

We have witnessed the failures of excessive market expansions where some fashion brands were diluted. Lacoste, a well-established French high-end apparel brand, was popular among many young people in the poorly developed outer suburban area of African. The expanded market segment of Lacoste conflicted with its brand positioning [7]. The company's advertising manager, Didier Calon, viewed the phenomenon during an interview in 2005: "It obviously had negative effects on the brand image. Certain of our consumers were upset that we could pursue this target, when in fact we have no control over it. Our sales decreased for three or four years..." [8]. The classic high-end British brand Burberry became popular with the British football casual cult during the 1970s, leading it to be associated with chavs, hooligans, and members of football companies by the 1990s. Even Burberry admitted that "Burberry is now synonymous with chavs and thugs" at that time [9]. To revitalize the brand, Burberry spent a huge amount of resources on the advertising campaign [10]. Pierre Cardin is another example of the fashion brand that overextended the market at the cost of degrading its brand value and losing shares in its primary target market. Pierre Cardin's licensing operations proliferated so much that the name had been lent to more than 800 products by the 1980s, including toilet-seat covers. In the end, despite his talents as a couturier, his name became too common for many high-fashion consumers [11]. A recent relevant observation is that when Louis Vuitton hired his new CEO who was formerly executive vice president of French food giant's division in the end of 2012, lots of connoisseurs worried that the management change provides a hint of 
its plan of entering the mass market that could dilute LV brand. These phenomena are known as "brand dilution," referring to the weakening of a brand due to its overuse. Brand dilution frequently happens as a result of unsuccessful brand extension [12-14].

Price cutting might increase sales volume but might also damage brand equity [11]. Brand extension, which extends the original brand to the new markets, could exert dilution effects on the parent brand when the attributes of extended brands are inconsistent with the original brand positioning [1,15-17]. Many related studies in fashion industry explained why some factors are critical for brand extension success [18-20]. This paper focuses on expanding the customer base to nontarget consumers by cutting price. This brand dilution factor results from social influences, such as conspicuous consumption $[2$, $3,11,20]$.

Han et al. [21] demonstrate with field experiments and market data that a market segment's preference for conspicuously (or inconspicuously) branded luxury product is significantly related with consumers' desire to be associated or dissociated with the members of that segment. Prior studies have identified two competing social needs among consumers: a need for uniqueness and a countervailing need for conformity $[22,23]$. Research in the area of reference group suggests the differences between consumer groups. For example, consumers from the elite group would like to distinguish themselves from the masses in consumption, but the masses seek to emulate the choices of the elites [24, 25]. Therefore, we build the model based on two groups of consumers, namely, the leader-group (LG) consumers and the follower-group (FG) consumers. LG consumers seek for the uniqueness and devalue a brand owned by too many FG, whereas FG consumers would like to follow LG and make the purchasing decisions when prices are acceptable $[7,26]$. Assuming that the fashion firm can change sales volume by adjusting product prices, we expect that the demand from FG will be increased when price is lowered. A higher demand of LG induces a higher demand of FG, while a higher demand of FG leads to a lower demand of LG.

The impact of brand dilution on firm performance is widely observed and discussed $[12,27,28]$, especially in fashion industry [29]. Some empirical studies measured the indexes of brand dilution and its moderating effect $[13,14,30$, 31]. Here we use the concept of brand purity to denote the degree of brand dilution that is defined in the mathematic model.

While many cases suggest the essential tradeoff that fashion brands need to make between increasing market share and degrading brand value, there is little research that has analyzed the dynamic mechanism of brand dilution. Therefore, we establish a dynamic brand dilution model and investigate analytically and numerically the situations where brand dilution occurs, the effects of brand dilution on brand firm performance, and the strategies to cope with brand dilution. The findings provide managerial implications for fashion firms regarding how to achieve the balance between market extension and brand dilution to optimize the firm performance.

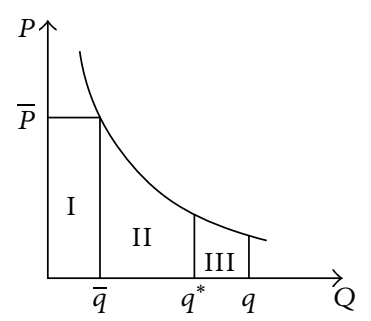

Figure 1: Demand curve and sales revenue.

For the numerical analysis, we use the System Dynamics (SD) that is a widely used methodology and mathematical modeling technique that clearly visualizes the model. By using SD model, the dynamic brand dilution model is vivid and is easier to understand. In addition, SD model is suitable to conduct stimulation for a particular case and to produce iteration results. It also acts as a delicate what-if tool for managers to conveniently modify specific variables of the model based on their needs and observe stimulation results under different conditions.

This paper contributes to the literature by (1) first introducing the idea of the brand purity and proposing a quantitative measure of brand dilution level; (2) establishing the dynamic brand dilution model; and (3) demonstrating analytically and numerically how dynamic changes of sales volumes affect the brand purity and the firm performance.

We develop an economic model for the mechanism of brand dilution in Section 2 and analyze the process of how brand dilution and firm performance develops in Section 3. The related system dynamics model and the numerical analysis appear in Section 4. Simulations on luxury fashion brand background further validate the process of brand dilution in Section 5. Conclusions are summarized in Section 6.

\section{Model}

2.1. Price-Sales Volume Relation. To simplify the configuration, we use demand curves to describe the relationship between the selling price and the quantity (sales volume) of a fashion brand in Figure 1. Given the existing product portfolio of the fashion brand, let $\bar{p}$ be the highest price of the branded products within the product portfolio and $\bar{q}$ the corresponding sales volume of these products. Within a certain period, price will be arbitrarily modified to adapt to the market, thus gradually falling below the starting price $\bar{p}$. Let $p=p(q)$, where $p>0, q>0, d p / d q<0, d^{2} p / d q^{2} \geq 0$, be the price function. The price function indicates that the final sale volume is $q$ if the final retail price is set at $p(q)$. The firm can reduce price to boost sales.

The revenue of the fashion brand is calculated by accumulating the product of the price and the quantity on the demand curve; for example, if the final price is $p(q)$, then the revenue of all the goods with $100 \%$ brand purity (the definition of brand purity and its effects on revenue are discussed later in this section) is given by the sum of areas I, II, and III in Figure 1. 
Price can effectively distinguish LG and FG consumers of the fashion brand [32]. For simplicity, we assume $p^{*}$ is the cutoff price for distinguishing these two types of consumers; that is, LG consumers only purchase the product of the brand when $p>p^{*}$, and FG consumers only purchase the product of the brand when $p \leq p^{*}$, where $p^{*}=p\left(q^{*}\right)$. The cutoff price $p^{*}$ between LG and FG is rational simplification to reality, in which LG and FG could have their own affordable price spans, and the two price spans can be overlapped or isolated. Note that $q^{*}$ is called the "critical point" of the sales volume that differentiates LG consumers and FG consumers.

Although brands can set price to control the sales volume, it is still difficult for them to prevent brand dilution, because they might not actually discern what is the exact $q^{*}$ and are easy to make actual sales volume bigger than the unknown $q^{*}$ (the lowest price is set lower than $p^{*}$ ), where FG consumers are involved and brand dilution occurs.

2.2. Brand Purity. The brand purity represents the mix of consumer amongst consumer groups. Let $q_{L}$ be the sales volume of LG consumers and $q_{F}$ the sales volume of FG consumers. The total sales volume is given by $q=q_{L}+q_{F}$. Let $s$ be the brand purity. We consider that the brand is pure with $s=1$ when only LG consumers purchase the products of the brand, and the brand is diluted with $s<1$ when FG consumers also purchase the products of the brand too. The smaller the $s$ is, the more the FG consumers purchase the products and the more the brand is diluted. Noting that the measure of the brand purity $s$ can be defined in many ways, $s=q_{L} /\left(q_{L}+q_{F}\right)$ is a simple example of the measure. However, it does not reflect the dynamic feature of the brand purity, so we do not adopt this measure. A dynamic brand purity measure is introduced in Section 2.3 later in this paper. The brand purity affects the purchasing intension of the LG consumers (but does not affect the purchasing intension of the FG consumers). For simplicity, we consider that, for $0 \leq$ $s \leq 1$, only $s$ portion of the demand of LG consumers will be transformed into the sales volume of the brand products.

For any given $0 \leq s \leq 1$ and the final price $p(q)$, the revenue of the brand for one selling season is given by

$$
\begin{gathered}
R=p(\bar{q}) \bar{q} s+\int_{\bar{q}}^{q} p(q) s d q, \quad \text { for } q \leq q^{*} \\
R=p(\bar{q}) \bar{q} s+\int_{\bar{q}}^{q^{*}} p(q) s d q+\int_{q^{*}}^{q} p(q) d q, \quad \text { for } q>q^{*}
\end{gathered}
$$

where $p(\bar{q}) \bar{q}$ is area I in Figure 1, $\int_{\bar{q}}^{q} p(q) d q$ is the front part of area II (for $q \leq q^{*}$ ), $\int_{\bar{q}}^{q^{*}} p(q)$ is area II in Figure 1 (for $q>q^{*}$ ), and $\int_{q^{*}}^{q} p(q) d q$ is III in Figure 1 (for $q>q^{*}$ ). Moreover, the profit of the brand for one selling season is given by

$$
O=(p(\bar{q})-c) \bar{q} s+\int_{\bar{q}}^{q}(p(q)-c) s d q-C, \quad \text { for } q \leq q^{*}
$$

$$
\begin{aligned}
O= & (p(\bar{q})-c) \bar{q} s+\int_{\bar{q}}^{q^{*}}(p(q)-c) s d q-C \\
& +\int_{q^{*}}^{q}(p(q)-c) d q-C, \quad \text { for } q>q^{*},
\end{aligned}
$$

where $c$ is the variable cost and $C$ is the fixed cost of the brand.

2.3. Dynamic Model. In this paper, we consider a multiple selling season situation (for simplicity, we consider 1 year for 1 selling season). In each year, the brand will push new products to the market. Denote by $s_{i}, R_{i}$, and $O_{i}$ (we use subscript to represent the year for all other notations), respectively, the brand purity, the revenue, and the profit of the brand, in the $i$ th year which are included, where $i$ is a nonnegative integer. We consider the dynamics model of the brand purity as follows:

$$
s_{i}=\alpha s_{i-1}+(1-\alpha) \frac{q_{L, i}}{q_{i}}, \quad s_{0}=1,
$$

where $0<\alpha<1, q_{L, i}$ is the sales volume of LG consumers in $i$ th year, and $q_{i}$ is the total sales volume of both LG and FG consumers. By noting the dynamic brand purity (3) follows the format of exponential weighted moving average (EWMA), that is, $s_{i}$ is the weighted sum on the last brand purity status $s_{i-1}$, and the current mix of the sales volume of the two groups of consumers $q_{L, i} / q_{i}$. We set $s_{0}=1$ and assume that there is no brand dilution at the beginning. Starting from the 1st year, the brand dilution begins when FG consumers start to purchase this brand. Let $q_{F, i}$ be the sales volume of FG consumers in the $i$ th year. By following (3), the degree of brand purity is accumulated from year 0 up to year $i-1$.

By following (1b), the revenue of the brand in year $i$ is

$$
\begin{aligned}
R_{i}= & p(\bar{q}) \bar{q} s_{i-1}+\int_{\bar{q}}^{q^{*}} p(q) s_{i-1} d q \\
& +\int_{q^{*}}^{q_{i}+\left(1-s_{i-1}\right) q^{*}} p(q) d q, \quad \text { for } p_{i}<p\left(q^{*}\right) .
\end{aligned}
$$

In (4), the base of LG consumers of year $i$ shrinks by an amount proportional to the brand purity $s_{i-1}$. As $q_{L, i}=s_{i-1} q^{*}$ and $q_{F, i}=q_{i}-s_{i-1} q^{*}$ when $p<p^{*}$, the final price will decline to $p\left(q_{i}+\left(1-s_{i-1}\right) q^{*}\right)=p\left(q^{*}+q_{F, i}\right)$ to obtain $q_{F, i}$ sales volume from FG. Moreover, the annual profit of the brand is given by

$$
\begin{aligned}
O_{i}= & (p(\bar{q})-c) \bar{q} s_{i-1}+\int_{\bar{q}}^{q^{*}}(p(q)-c) s_{i-1} d q \\
& +\int_{q^{*}}^{q_{i}+\left(1-s_{i-1}\right) q^{*}}(p(q)-c) d q-C, \quad \text { for } p_{i}<p\left(q^{*}\right) .
\end{aligned}
$$

When the fashion brand wants to achieve more annual revenue and profit through lowering the price to enlarge the sales volume, brand dilution, which will undermine the firm performance (revenue and profit), occurs once the sales volume exceeds the critical point $q^{*}$ and FG consumers are attracted to the brand. 


\section{Analysis}

The increase of sales volume of the fashion brand is often considered as an indicator of brand growth. Under the pressure from the stakeholders, the brand is highly motivated to continue increasing its sales volume overtime. Although, to increase the sales volume, the brand has to decrease marginal price, it still has plenty of space to cut prices, as the price of fashion product is usually significantly higher than the product cost. The growth mechanisms of brands with a pure brand $(s=1)$ and with diluted brand $(s<1)$ are different as we discuss below.

3.1. The Brand Is Pure. When the brand is pure, increasing sales volume is a good strategy for a firm to enjoy continued increasing revenue and profit.

Proposition 1. Suppose that $s_{i-1}=1 ; s_{i}<1$ only if sales volume $q_{i}>q^{*}$ (or $\left.p_{i} \leq p\left(q^{*}\right)\right)$. (All proofs are presented in Appendix A.)

Discussion of Proposition 1. As shown in Proposition 1, dilution does not occur when only LG consumers purchase the products, or dilution occurs until FG consumers start to purchase the brand.

Proposition 2. Suppose that $s_{i-1}=1$; if $s_{i}=1, R_{i}$ and $O_{i}$ are both increasing functions of $q$.

Discussion of Proposition 2. As the maximum $q$ that keeps the brand pure is $q^{*}$ (by Proposition 1), according to Proposition 2, the revenue and the profit of the brand are maximized at $q=q^{*}$ when the brand is pure, and cutting price to increase sales (less than $q^{*}$ ) volume leads to positive consequences (higher revenue and profit) over years.

3.2. The Brand Is Diluted. Once the firm gets used to the experience of benefiting from increasing sales volume, the firm may have the tendency to oversell the products to FG consumers and suffer the negative impacts of brand dilution. To focus on brand dilution effects, our analysis starts from the critical point of brand dilution. Moreover, for simplicity, we assume that the fashion brand firm will increase sales volume at an annual rate of $\theta_{i}>0$. Hence, the sales volume in year $i$ is given by

$$
q_{i}=q^{*} \prod_{j=1}^{i}\left(1+\theta_{j}\right), \quad q_{0}=q^{*} .
$$

Following the changes in sales volume, the brand purity is also altered:

$$
\begin{aligned}
s_{i} & =\alpha s_{i-1}+(1-\alpha) \frac{q_{L, i}}{q_{i}} \\
& =\alpha s_{i-1}+(1-\alpha) \frac{q^{*} s_{i-1}}{q^{*} \prod_{j=1}^{i}\left(1+\theta_{j}\right)} \\
& =\left(\alpha+\frac{1-\alpha}{\prod_{j=1}^{i}\left(1+\theta_{j}\right)}\right) s_{i-1},
\end{aligned}
$$

or

$$
s_{i}=\prod_{k=1}^{i}\left(\alpha+\frac{1-\alpha}{\prod_{j=1}^{k}\left(1+\theta_{j}\right)}\right) .
$$

According to (8), $s_{i}$ will decrease at an accelerating rate of $\left(\alpha+(1-\alpha) /(1+\theta)^{i}\right)$; namely, the brand purity will be eroded severely as the sales volume continues to rise. The brand will gradually lose its superiority to LG consumers who contribute the majority of its revenue, inevitably resulting in a shrinking of LG consumer base.

Proposition 3. If $s_{0}=1$ and $s_{i}$ is given by (8), with $\theta_{i}>0$, $i=1,2, \ldots$, then $s_{i+2} / s_{i+1}<s_{i+1} / s_{i}<1$.

Discussion of Proposition 3. Once the increasing sale volume exceeds the critical point $q^{*}$ and the brand purity declines, the process of brand dilution will accelerate, as sales volume keeps increasing. So things will deteriorate swiftly when brand dilution happens. Is there anything we can do for it? For example, to keep the annual sales volume unchanged after brand dilution occurs, let $H>1$ be an integer.

Proposition 4. Suppose that $\theta_{k}>0$ for $k=1, \ldots, H-1$ and $\theta_{k}=0$ for $k \geq H$. If $s_{i}$ is given by (8), then $s_{i+2} / s_{i+1}=s_{i+1} / s_{i}<$ 1 for $i>H$.

Discussion of Proposition 4. Once the brand purity starts to decline, stopping increasing the sales volume cannot prevent the deterioration, and the brand purity will still decrease at a constant rate. This case is a little bit better than decreasing at an accelerating rate but is still bad because it cannot stop the brand to ruin. So how about cutting the sales volume after the brand is diluted?

Proposition 5. $s_{i} \geq s_{i-1}, i \in N$, if and only if $q_{i} \leq q^{*}$.

Discussion of Proposition 5. Once the brand purity declines, the firm can enhance brand purity by reducing sales less than $q^{*}$. Noting that sales volume is less than $q^{*}$ does not imply all the sales volume is made up of LG consumers, especially fashion brand which had ever diluted. To enhance brand image, sales volume of current year should be confined within the range. In other words, only cutting sales volume a little cannot promise improving the brand purity when it already exceeds the critical point $q^{*}$. Therefore, brand purity will continue to decline unless sales volume decreases to below $q^{*}$. However, in practice, recovering a diluted brand is always difficult because firms are often reluctant to adopt such radical method. Moreover, Proposition 5 once again shows the importance of the critical point $q^{*}$. No matter how many exceeding sales volume accumulated by years, to return to the critical point is the key for keeping brand purity.

To make the model more comprehensive, the constraint on the annual sales volume is relaxed as $\theta_{i}>-1$. So the annual sales volume can be increased $\left(\theta_{i}>0\right)$ or be decreased $\left(-1<\theta_{i}<0\right)$. Note that, for this case, $q_{i}=q^{*} \prod_{j=1}^{i}\left(1+\theta_{j}\right)<$ $q^{*} s_{i-1}$ could occur. As $q^{*} s_{i-1}$ is the maximum sales volume of LG in year $i$, if $q_{i}<q^{*} s_{i-1}$, then $q_{L, i}=q_{i}$; that is, only LG 
consumers purchase the brand in year $i$. Together with the fact that demand of LG consumers is always be fulfilled first, we have $q_{L, i}=\min \left\{q^{*} s_{i-1}, q_{i}\right\}$. Moreover, $q_{i} \leq q^{*} s_{i-1}$ means that not all the demand of LG consumers of year $i$ will be fulfilled. In other words, the brand controls the annual sales volume to meet part of LG's demand only. The brand purity becomes

$$
s_{i}= \begin{cases}\alpha s_{i-1}+(1-\alpha) \frac{q_{L, i}}{q_{i}}, & \text { for } q_{i}>q_{L, i}, \\ \alpha s_{i-1}+(1-\alpha), & \text { for } q_{i}=q_{L, i} .\end{cases}
$$

If $q_{i}>q_{L, i}$, for all $i \in N$ ( $N$ denotes natural number), that is, $q^{*} \prod_{j=1}^{i}\left(1+\theta_{j}\right)>q^{*} s_{i-1}$, the equation can be deduced as same as (8), even through $\theta_{i}$ can be less than 0 . If $q_{i}=$ $q_{L, i}$, the $i$ th increment of the sales volume in year $i$ is $\theta_{i}<$ $\left(s_{i-1} / \prod_{j=1}^{i-1}\left(1+\theta_{j}\right)\right)-1$, which means the firm will cut the sales volume dramatically that very few brands would adopt it.

Next, we explore the impacts of the annual sales volume on the revenue and profits.

Proposition 6. Suppose that $\theta_{k}>0$ for $k=1, \ldots, H-1$ and $\theta_{k}=0$ for $k \geq H$. If $s_{1}<1$, then $R_{i}<R_{i-1}, O_{i}<O_{i-1} O_{i}-$ $\mathrm{O}_{i-1}<0$ for all $i>H$.

Discussion of Proposition 6. Once the brand is diluted, even if the sales volume remains unchanged thereafter, the annual revenue and profit will continue to decline.

Then what if the sales volume continues to increase after the brand is diluted? What is the speed of decline of the annual revenue and profit? And what are the factors that account the fluctuation? Proposition 3 indicates that the process of dilution will accelerate, once sales volume exceeds the critical point and keeps increasing every year. The revenue and profit could decline because newly added FG consumers will make part of LG consumers leave. Thus, the profit drops. However, it is possible that the negative effects of reduced revenue and profits caused by shrinking LG consumer base can be compensated by the benefit of an enlarged consumer size due to the expansion to FG consumers. It is the net effect of these variations that determines the impact of brand purity. Meanwhile, the direction and magnitude of changes of revenue and profit are uncertain due to the influence of factors such as specific shape of demand (or sales) curve, growth rate, and other variables.

To answer these questions, as a further step, we conduct numerical stimulations, which enable us to have a clearer picture of the interactions of different factors and how they affect the revenue and profit. Specifically, we use the SD that is a widely used methodology and mathematical modeling technique that clearly visualizes the model. Moreover, by using SD model, the demonstration of propositions raised above will be vivid and easier to understand (the results are available from the authors upon request).

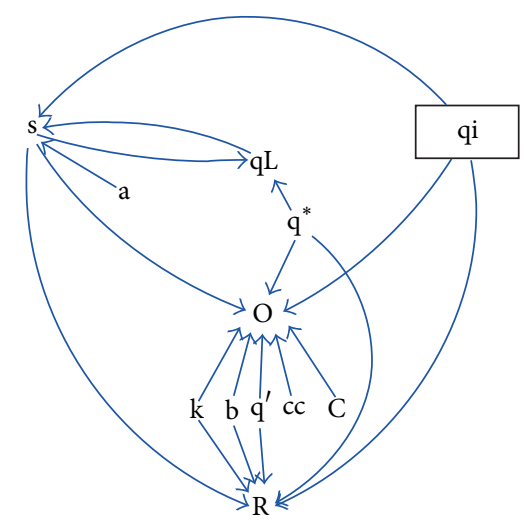

Figure 2: Causal loop diagram of the model.

TABLE 1: Correspondence between mathematics model and SD model.

\begin{tabular}{lc}
\hline Variables in mathematics model & Variables in SD model \\
\hline$q_{i}$ & $\mathrm{qi}$ \\
$q^{*}$ & $\mathrm{q} *$ \\
$q_{L, i}$ & $\mathrm{qL}$ \\
$\alpha$ & $\mathrm{a}$ \\
$\bar{q}$ & $\mathrm{q}^{\prime}$ \\
$C$ & $\mathrm{C}$ \\
$c$ & $\mathrm{cc}$ \\
$s_{i}$ & $\mathrm{~s}$ \\
$R_{i}$ & $\mathrm{R}$ \\
$O_{i}$ & $\mathrm{O}$ \\
\hline
\end{tabular}

\section{System Dynamics Model (Numerical Analysis)}

The mathematical model in Sections 2 and 3 can also been presented by an SD model. SD method is an effective tool for numerical analysis and simulation. The modeling process mainly consisted of two parts: causal loop diagram(s) and mathematical expressions accordingly. The model can help identify the essential factors that positively or negatively affect firm performance by increasing sales volume.

4.1. Causal Loop Diagram. Equation (4) helps build the causal loop diagram accordingly. The variable $q_{i}$ is the sales volume of year $i$, which is set as a cumulative quantity (stocks). Its dynamic change (flow) is proportional to its size denoted by $\theta_{j}$ in (6). Variable $s_{i}$, the brand purity in (3), is affected by the sales volume of the $i$ th year $q_{i}$, the sales volume of $i$ th year from LG $q_{L, i}$, and the cumulative weight of brand purity $\alpha$. Similarly, the annual revenue $(R)$ and the annual profit $O$ could be linked together as in Figure 2, according to (4) and (5), respectively. We use Vensim PLE V5.11 as SD tool, which helps present the causal loop diagram as Figure 2.

In Vensim, the names of the variables do not include the superscripts, subscripts, and Greek letters. Therefore the names of variables in the mathematics model are different from the names in the SD model, while both models represent 
the same thing. Table 1 shows the corresponding variable names between the two models.

In the SD model, the $k$ and $b$ are parameters for the demand curve function $p=p(q)$. In the linear function, $k$ is slope, and $b$ is intercept on ordinate (showed in Section 4.3).

4.2. Mathematical Expression in SD. An SD model for simulation should use a concrete function with numerical parameters. We present an SD model example by formulating it with the linear demand curve $p(q)=b-k q$ with $b=1400$ and $k=0.02$. For example, the derived firm's annual revenue $R_{i}$ from (4) is

$$
\begin{aligned}
R_{i}= & (b-k \bar{q}) \bar{q} s_{i-1}+\left(2 b-k\left(q^{*}+\bar{q}\right)\right)\left(q^{*}-\bar{q}\right) s_{i-1} \\
& +\left(2 b-k\left(q_{i}+\left(1-s_{i-1}\right) q^{*}+q^{*}\right)\right) \\
& \times\left(\left(q_{i}+\left(1-s_{i-1}\right) q^{*}+q^{*}\right)\right) .
\end{aligned}
$$
is

The corresponding formula in Vensim PLE, the SD tool,

$$
\begin{aligned}
\mathrm{R}= & (\mathrm{b}-\mathrm{k} * \mathrm{q} \prime) * \mathrm{q} \prime * \operatorname{DELAY} 1(\mathrm{~s}, 1) \\
& +\left(\frac{1}{2}\right) *\left(2 * \mathrm{~b}-\mathrm{k} *\left(" \mathrm{q} * "+\mathrm{q}^{\prime}\right)\right) \\
& *\left(" \mathrm{q} * "-\mathrm{q}^{\prime}\right) * \operatorname{DELAY} 1(\mathrm{~s}, 1)+\left(\frac{1}{2}\right) \\
& *(2 * \mathrm{~b}-\mathrm{k} *(\mathrm{qi}+(1-\operatorname{DELAY} 1(\mathrm{~s}, 1)) * " \mathrm{q} * "+\mathrm{q} * ")) \\
& *(\mathrm{qi}+(1-\operatorname{DELAY} 1(\mathrm{~s}, 1)) * " \mathrm{q} * "-" \mathrm{q} * ") .
\end{aligned}
$$

Because the "*" in variable $\mathrm{q} *$ could be recognized as product sign, variable $\mathrm{q} *$ is represented as " $\mathrm{q} *$ " in the tool. To be consistent with this style, all formulas in Section 2 are filled into the causal link (in Figure 2). The whole mathematic formulae in SD model are shown in Appendices B and C. Models engaged with other demand curves as below are produced likewise by set of corresponding demand curve parameters, respectively.

4.3. Results. To investigate how annual revenue and profit will change when the sales volume expands beyond the LG consumer base and leads to brand dilution, in the following part, we simulate 3 different types of general demand curve: (1) straight line; (2) fold line; (3) convex curve.

Several assumptions are set: a fashion brand increases 10\% of sale volume per year; at the 10th year the sales volume reaches the critical point $q^{*}$, which means during the 0 10th years the sales volume covered only the LG consumers, and the brand purity is kept to be 1; from the 11th year, the marginal increased sales volume comes from FG consumers, brand begins diluting, and some LG consumers abandon the brand. In Sections 2 and 3, we discuss propositions from year of initial brand dilution; so $i=0$ in Sections 2 and 3 is equal to $i=10$ in this section. Similarly, $i=1$ above is equal to $i=11$ here, and so on. We insert 10 years period of prelude, in order to show and contrast what happens before and after brand dilution.
TABLE 2: Straight line with various slopes.

\begin{tabular}{lccc}
\hline Line & $b$ & $k$ & $\left(p^{*}, q^{*}\right)$ \\
\hline 1 & 5000 & 0.20 & $(1000,20000)$ \\
2 & 4000 & 0.15 & $(1000,20000)$ \\
3 & 3000 & 0.10 & $(1000,20000)$ \\
4 & 2600 & 0.08 & $(1000,20000)$ \\
5 & 2000 & 0.05 & $(1000,20000)$ \\
6 & 1400 & 0.02 & $(1000,20000)$ \\
7 & 1200 & 0.01 & $(1000,20000)$ \\
\hline
\end{tabular}

4.3.1. Straight Line. Choose different slopes and intercepts in $p(q)=b-k q$ as below. In order to compare conveniently, assume the critical point $\left(p^{*}, q^{*}\right)$ between LG and FG is (1000, 20000), and all straight lines pass through this point.

Figure 3 shows the result of the simulation test when $\alpha=$ 0.8 . As the slope gets gentler ( $k$ gradually decreases), the turndown year of annual revenue and profit happens later and later (from line 1 to line 7). In Figure 3 annual profits of lines 1 and 2 turn down at 12th; those of lines 3 and 4 do at 13th; those of lines 5, 6, and 7 do at 14th, 18th, and 24th. Annual revenues of those lines have similar features. In other words, with sales growth of $10 \%$ annually, when the brand dilution starts (after the 10th year), the slope of lines mainly decides how fast the bad effect on fashion firm performance (drop of annual revenue and profit) appears because of brand dilution. What is more is brand dilution is often tricky and does not show its true faces immediately. Firms frequently did not find the problem until it had become heavy. As lines 5, 6, and 7, brand dilution happened at the 11th year but would show its true faces after growing several years.

If all the other parameters remain the same and change the accumulated weighted average index into $\alpha=0.5$ (Figure 4), which means that the brand dilution's impact in the current year plays a more important role than the accumulation by past years, the dilution process will go faster. In general, the decrease of annual revenue and profit starts earlier, and other characteristics are in line with Figure 3. Thus, the influence of $\alpha$ is not as strong as the slope. Therefore, the following simulations will use $\alpha=0.8$ as examples to demonstrate the situations.

4.3.2. Fold Line. Generally, the scale of LG is always somewhat smaller than that of the FG. So the demand curve of the LG is more slanting than that of FG. To better reflect the demand elasticity of the two groups, fold lines are adopted in Figure 5(a). As above, the former part of the fold lines represents sales to LG, and the latter represents the sales to FG. As the straight lines, $(1000,2000)$ points remain as the critical point which is set as the fold point of each fold line.

Figure 5(b) numerates fold lines with 8 combinations. Table 3 lists these combinations and the number of line corresponding to Table 2 .

In Figure 6, the simulation test reveals that from the 10th year since the brand dilution started, as the sales volume keeps increasing, whether the annual revenue and profit fall or not mostly depends on the slope of the fold line pair. If both 

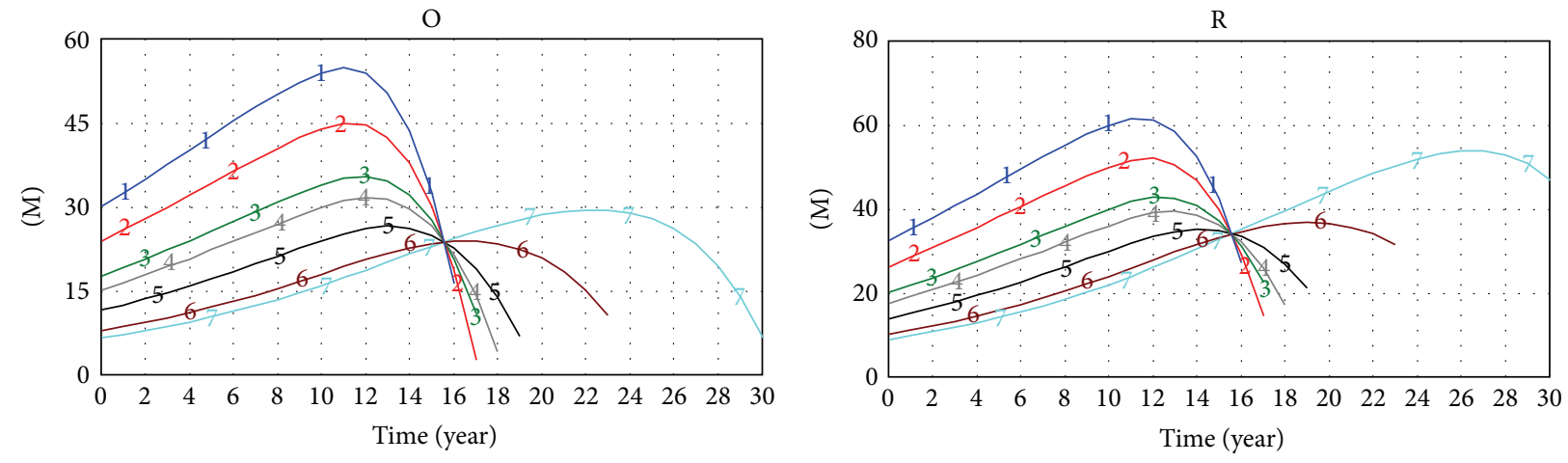

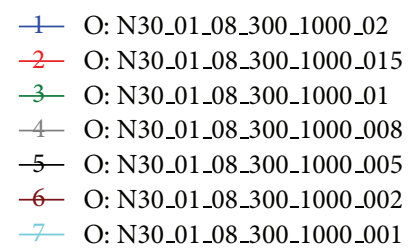

(a)

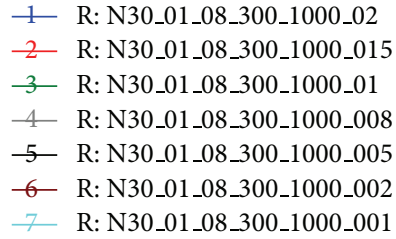

(b)

FIGURE 3: Annual revenue and profit under various straight lines $(\alpha=0.8)$.
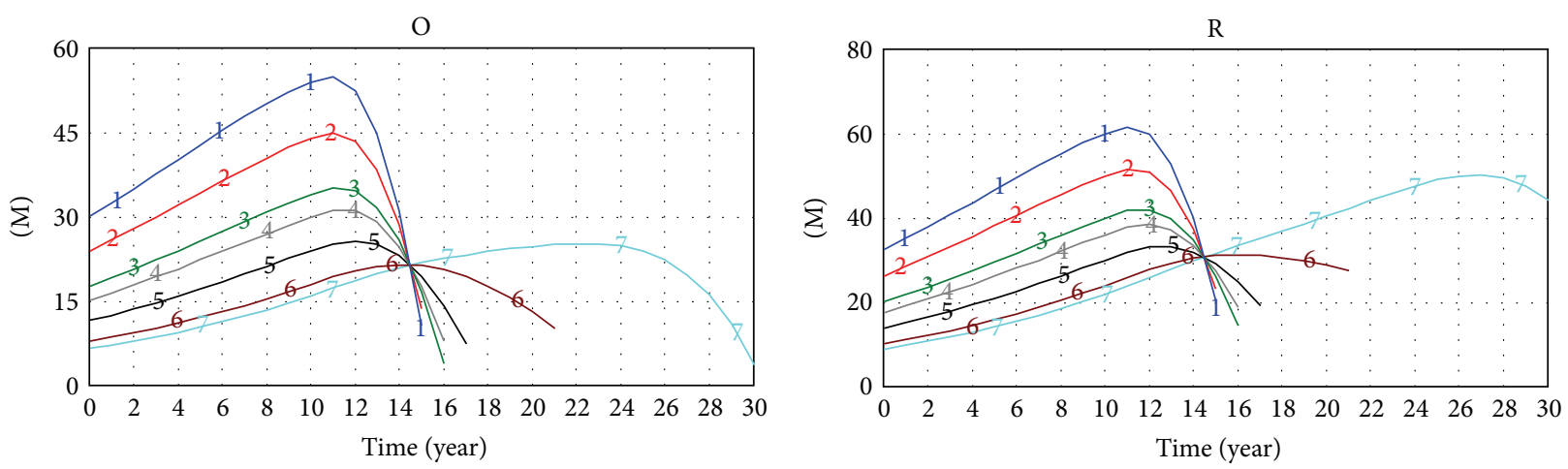

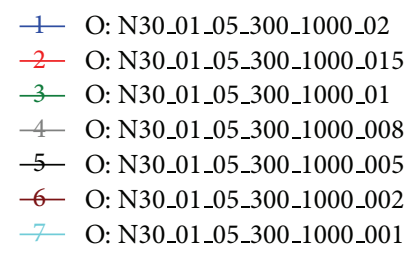

(a)

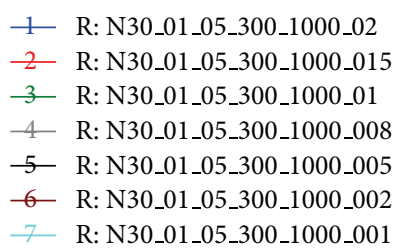

(b)

FIGURE 4: Annual revenue and profit under various straight lines $(\alpha=0.5)$.

parts slant a lot (e.g., the combination of fold line 1 in Table 3), significant decrease will appear earlier; on the contrary (e.g., the combination of fold line 8 in Table 3), decrease will appear later or even not appear. This is consistent with the simulation results of the straight lines. From fold lines 1-4 in the first group and fold lines 5-6 in the second group (Figure 6), we can see that when the former part of the fold line remains the same, if the latter part is less slanting, performance decrease will appear more delayed. Comparing fold lines 1 and 5 (or 2 and 4, $3 \& 7,4$ and 8), we can conclude that while the slope of the latter part remains constant, the less slanting the former part is, the latter the performance decrease will occur. It could be dangerous for fashion brand firms, if brand dilution does not signal immediately, because firms could not be aware of the constant losing of LG with the increasing sales volume, and actions to remedy the harmful brand dilution will delay. On the other side, if the slope of the latter part of fold line is gently (much more elastic), which means that demand from FG is much greater than LG, it is feasible that the fashion firm will not interfere with the brand dilution even if the brand was degraded. However, to compare these two strategies requires another paper to discuss. 


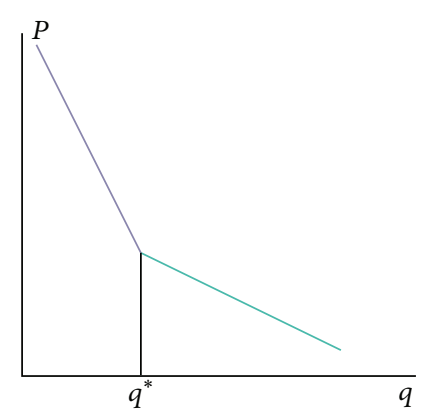

(a)

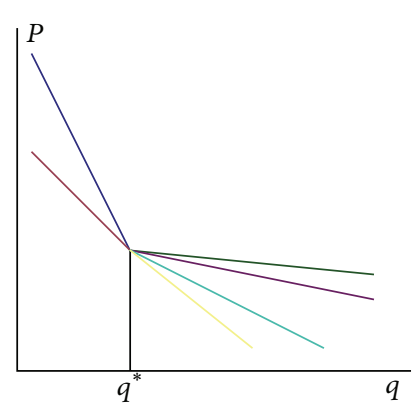

(b)

Figure 5: (a) $p(q)$ of fold line. (b) $p$ ( $q$ ) of fold lines pairing.

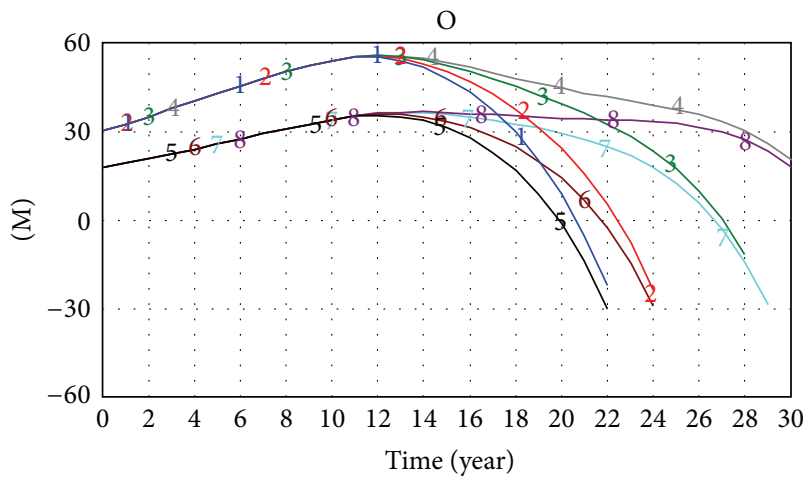

- O: N30_01_08_300_1000_02_008
$-2-$ O: N30_01_08_300_1000_02_005
$-3-$ O: N30_01_08_300_1000_02_002
$-1-$ O: N30_01_08_300_1000_02_001
$-5-$ O: N30_01_08_300_1000_01_008
$-6-$ O: N30_01_08_300_1000_01_005
$7-$ O: N30_01_08_300_1000_01_002
- - O: N30_01_08_300_1000_01_001

(a)

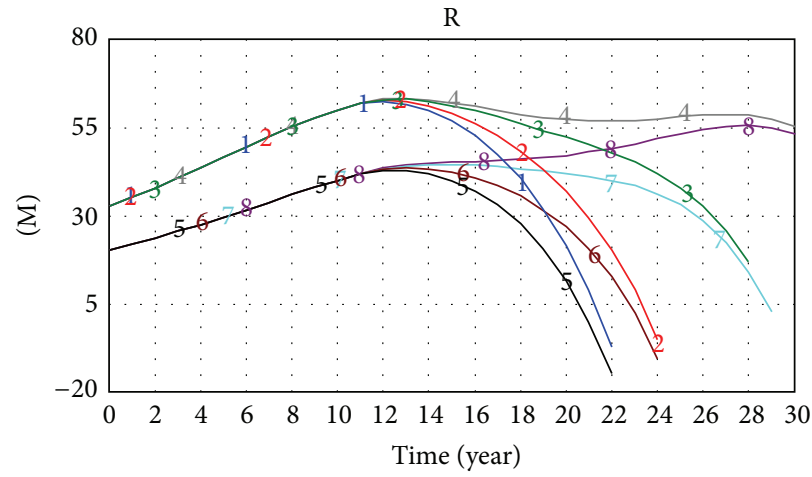

1 R: N30_01_08_300_1000_02_008

2 R: N30_01_08_300_1000_02_005

3- R: N30_01_08_300_1000_02_002

-1 R: N30_01_08_300_1000_02_001

5- R: N30_01_08_300_1000_01_008

6 - R: N30_01_08_300_1000_01_005

7 R: N30_01_08_300_1000_01_002

8 R: N30_01_08_300_1000_01_001

(b)

FIgURE 6: Annual revenue and profit under various fold line pairs.

Proposition 7. Once brand purity declines, whether the annual revenue and profit will rise or drop is mainly decided by the elasticity of demand curve of both LG and FG: the less elastic (bigger of slope) the LG demand curve is, the higher the probability for the annual revenue and profit to drop is; the more elastic (smaller of slope) the FG demand curve is, the higher the probability for the annual revenue and profit to rise is.

Discussion of Proposition 7. The demonstration in straight line above has showed the property, as well as the fold line situation here. The bigger the slope of the front part of fold line is (demand curve of LG), the greater the loss in revenue and profit generated from those high-end consumers is. As the nadirs of the former part of fold lines are same, the greater the slope is, the bigger the area in the part II in Figure 1 is. Bigger area with multiple same proportion loss of consumer produces a bigger drop of revenue and profit.
On the other side, the smaller the slope of the hind part is (demand curve of FG), the greater the increment in revenue and profit generated from those FG consumers is.

In the following, some typical convex curve examples will show if Proposition 7 works.

4.3.3. Convex Curve. Here we use common convex curve function, $p(q)=k / q^{b}$. Table 4 presents 5 different curves with various $k$ and $b$.

For easier comparison, the parametric setting of these curves allows them to pass through or be extremely close to the critical point $\left(p^{*}, q^{*}\right)$. The graph is presented in Figure 7.

The results of the curve got from the simulating test are consistent with those of the fold lines. Because the slope near the critical point in lines 1 and 2 is greater, the decrease of annual revenue and profit occurs earlier (Figure 8); since 
TABLE 3: Fold lines pairing composition in Figure 5(b).

\begin{tabular}{lcccccc}
\hline Fold Line & Line & $b$ & $k$ & $\left(p^{*}, q^{*}\right)$ & Line & $b$ \\
\hline 1 & 1 & 5000 & 0.20 & $(1000,20000)$ & 4 & 2600 \\
2 & 1 & 5000 & 0.20 & $(1000,20000)$ & 5 & 2000 \\
3 & 1 & 5000 & 0.20 & $(1000,20000)$ & 6 & 1400 \\
4 & 1 & 5000 & 0.20 & $(1000,20000)$ & 7 & 0.05 \\
5 & 3 & 3000 & 0.10 & $(1000,20000)$ & 4 & 0.02 \\
6 & 3 & 3000 & 0.10 & $(1000,20000)$ & 5 & 2600 \\
7 & 3 & 3000 & 0.10 & $(1000,20000)$ & 6 & 2000 \\
8 & 3 & 3000 & 0.10 & $(1000,20000)$ & 7 & 0.01 \\
\hline
\end{tabular}

TABLE 4: Convex curve $p(q)$ with various parameters.

\begin{tabular}{lccc}
\hline Curve & $b$ & $k$ & $\left(p^{*}, q^{*}\right)$ \\
\hline 1 & $3 / 2$ & 2828430000 & $(1000,20000)$ \\
2 & $4 / 3$ & 542884000 & $(1000,20000)$ \\
3 & 1 & 20000000 & $(1000,20000)$ \\
4 & $2 / 3$ & 736806 & $(1000,20000)$ \\
5 & $1 / 2$ & 141421 & $(1000,20000)$ \\
\hline
\end{tabular}

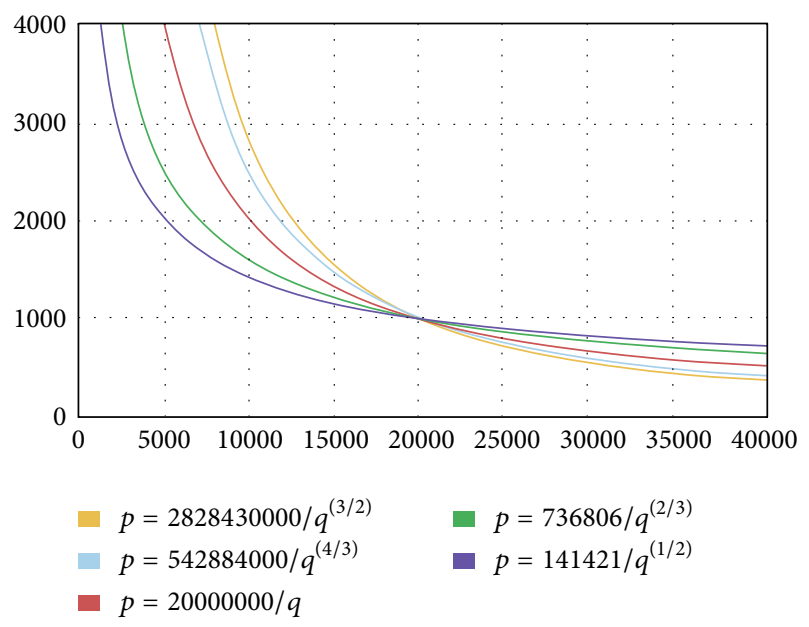

FIGURE 7: Convex curves with various parameters.

the slope near the critical point in lines $4 \& 5$ is gentler, obvious decrease does not occur at observed period.

From the above numerical analysis, we can see that, after brand purity decline happens, when sales increase, the change of sales revenue and profit will be determined by the mutual effect of the following two parts: (A) the loss of revenues and profit resulting from the sales decrease due to the loss of the LG consumers, which is negative; (B) the increase of revenues and profit resulting from the sales increase due to the marginal increasing FG consumers, which is positive. Obviously, this relationship will most strongly affect the slope of the demand curve before and after the $q^{*}$. The steeper the part before $q^{*}$ is, the bigger A will be; the flatter the part after $q^{*}$ is, the bigger B will be. Proposition 7 works in convex curve situations (We have test simulation under 20\%/year increment on sales volume and get similar results as $10 \%$ increment. We would like to provide the simulation result to anyone interested.).

Along with the propositions in Sections 2 and 3 and the simulation in Section 4, this model well describes the impacts that brand purity has exerted on annual revenue and profit of fashion firms. This model severs as a good reference when analyzing the influence of brand purity on firm performance under different circumstances.

\section{Application Simulation for Different Strategies of Sales}

In order to better demonstrate the application of the model, this section discusses, in the context of fashion luxury brands, how brand purity and the firm performance differ when using different strategies of sales. Fashion luxury brand is chosen as the context because the luxury brand, compared to other factors, has greater influence on the price of the product. For the simulation, we choose a set of parameters that reflect the luxury brand context well. Due to the difference in the purchasing power of the LG and the FG, the slopes of demand curve for LG and FG are different in general. The differences are exhibited by the convex curve. An intuitive observation suggests investigating a model in the form of the SD model. Take line 3, displayed in Table 4, as the original demand curve: $p(q)=k / q$. In order to be closer to the real scenario, parameters are set as follows: $k=20000000, \bar{q}=1000$, $q^{*}=20000, c=300$, and $C=20000000$. In reality, luxury brands such as LV, the annual sales volumes of each category are generally 2 millions, 100 times of $q^{*}=20000 . \mathrm{k} / q^{*}=1000$ dollar (pecuniary unit is dollar if not state) and $k / \bar{q}=20000$ are, respectively, the minimum and the maximum prices of an LV product in principle. Fashion firms often adopt the price strategy of high-priced new arrival and off-season discounts or provide different types of products among the 1000-20000 price range. The variable cost $c=300$ is one of the main factors of unit cost that are related to the quantity change. The variable cost includes marketing costs, additional labor costs, and costs of variable inputs. $C=20000000$ is annual fixed cost, which generally represents the corporate cost. To observe the trend of firm profits, factor $C$, served as a constant, is almost negligible.

We conduct the following simulations to illustrate two common problems of fashion brands. (1) Firms are vulnerable to suffering band dilution when they are blinded by their 


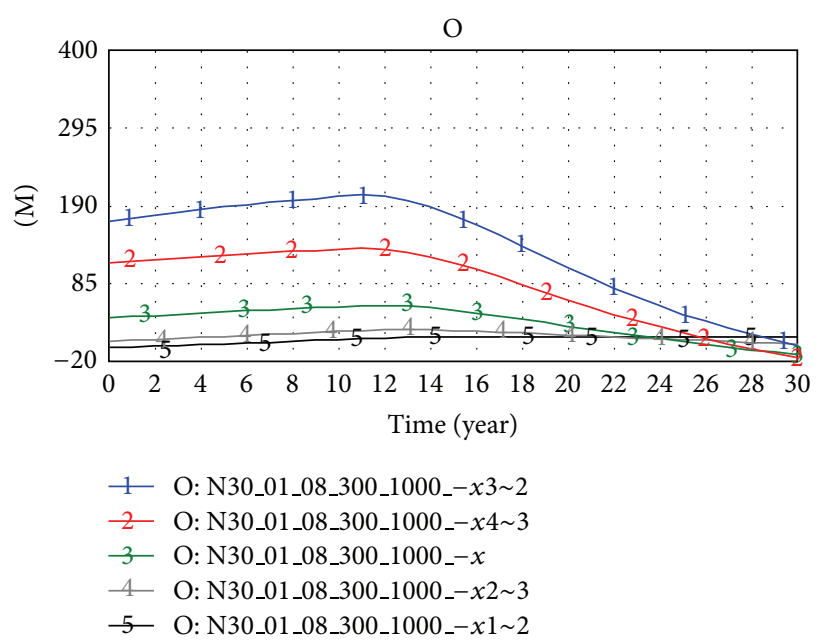

(a)

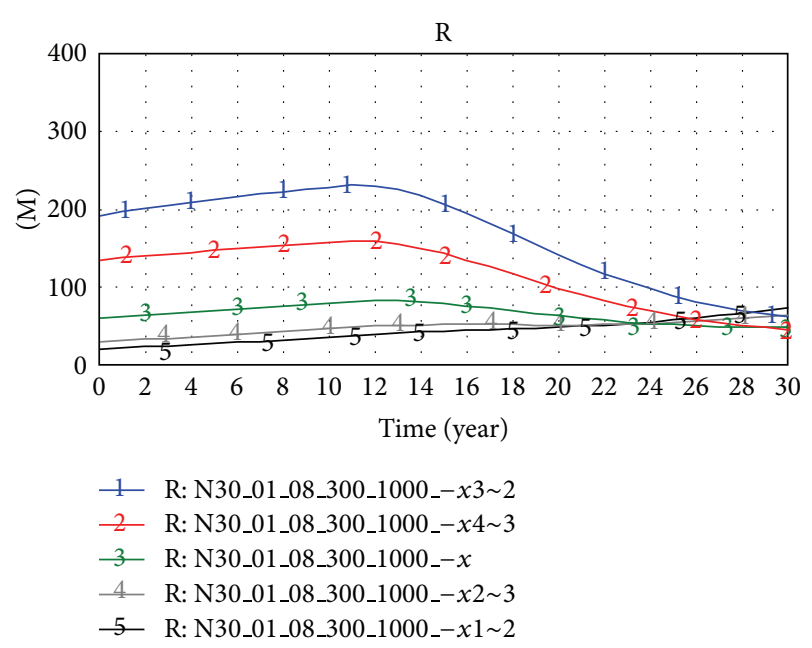

(b)

FIGURE 8: Simulation results of the 5 curves in Table 4.

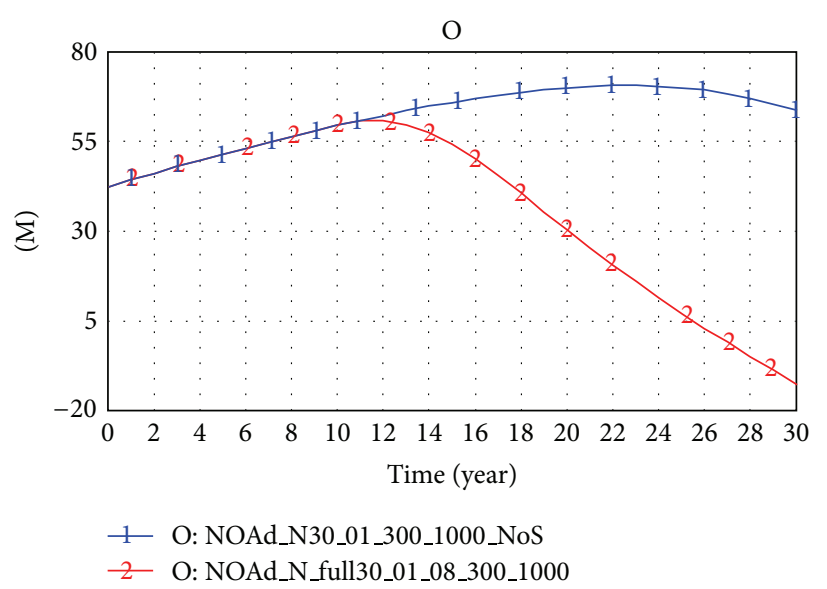

(a) Annual profit

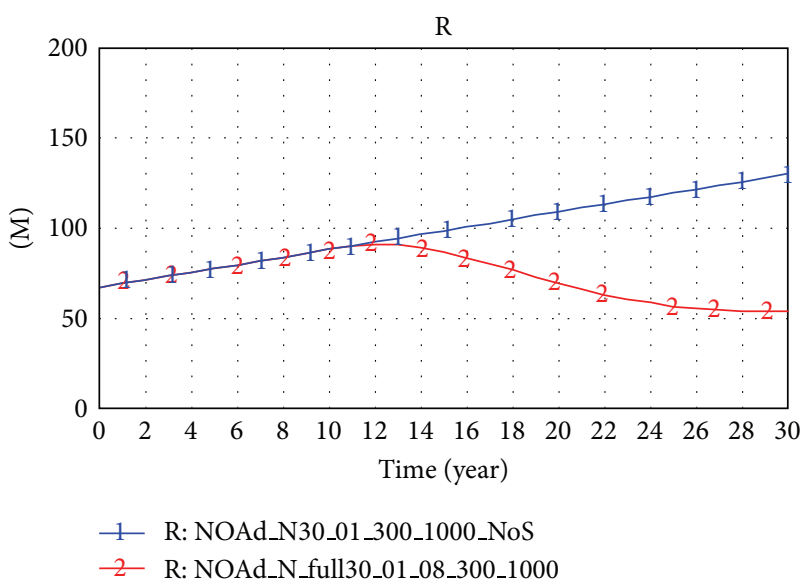

(b) Annual revenue

FIgURE 9: Contrast of two cases: without (line 1) and with brand purity decline (line 2).

strong motivation of growing business. (2) Different sales strategies can change brand purity and affect firm performance.

5.1. Two Cases of Brand Dilution. Maximizing profitability is the objective of many businesses, and increasing sales volume is the common tactics often used by not only fashion firms but also many other firms to enhance profits. However, firms may be stuck in the following two brand dilution problems, if they do not manage the increase of sales volume cautiously.

\subsubsection{Case 1: Consumer Group Has Not Yet Been Segmented.} If the target fashion brand consumers can be, but are not, divided into potential LG and FG, the firm could encounter unexpected performance deterioration due to indulging in enlarging sales volume to enhance profit. The example will show the difference between expectation (line 1 in Figure 9) and unexpected result (line 2 in Figure 9).
Example 8. Set the corresponding parameters as the basic set, and $\alpha=0.8, \theta=10 \%$. Contrast the two situations with and without brand purity decline.

The firm may expect the sales volume to increase in this way: the demand increases as the marginal price decreases. As long as the declined product price is greater than the product variable cost, the firm is able to earn profit. Therefore, with continuing growth of sales volume, annual profit will increase until the 23rd year. However, with the unknown influence of brand dilution, LG consumers keep abandoning this brand, which causes profit decreases 2 years later after sales volume exceeds the critical point at 10th year. That is beyond the firm's expectation.

5.1.2. Case 2: The Boundary of FG and LG Is Unknown. The model simulation shows that expanding market share in LG through continuously raising sales volume benefits firms' 


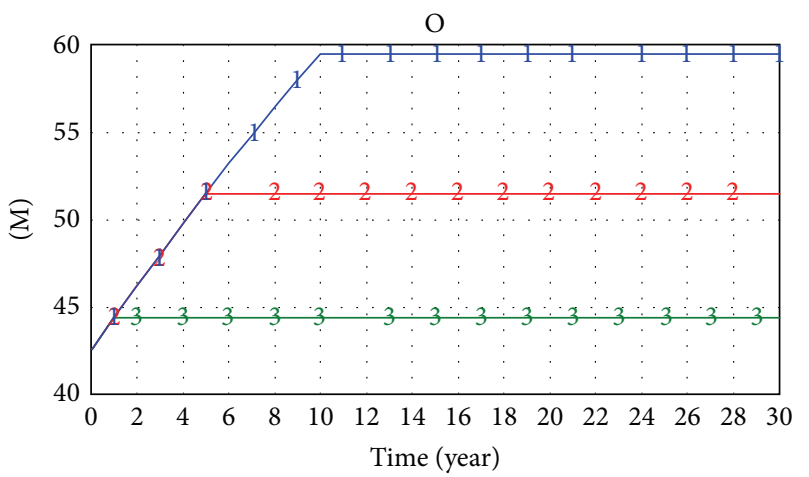

$1-$ O: NOAd_N_full30_01_08_300_1000_10keep
$2-$ O: NOAd_N_full30_01_08_300_1000_5keep
$-3-$ O: NOAd_N_full30_01_08_300_1000_1keep

(a) Annual profit

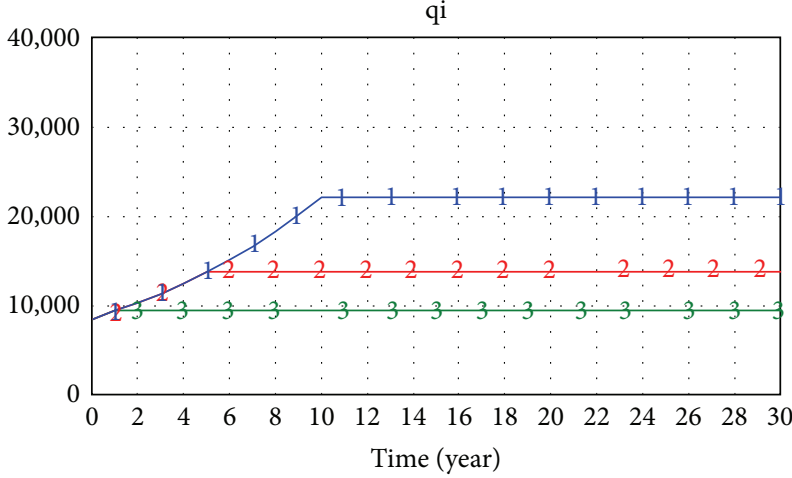

1 qi: NOAd_N_full30_01_08_300_1000_10keep

2 qi:NOAd_N_full30_01_08_300_1000_5keep

3 - qi: NOAd_N_full30_01_08_300_1000_1keep

(b) Annual sales volume

FIGURE 10: Contrast of profits resulting from different sales volumes in the LG target group.

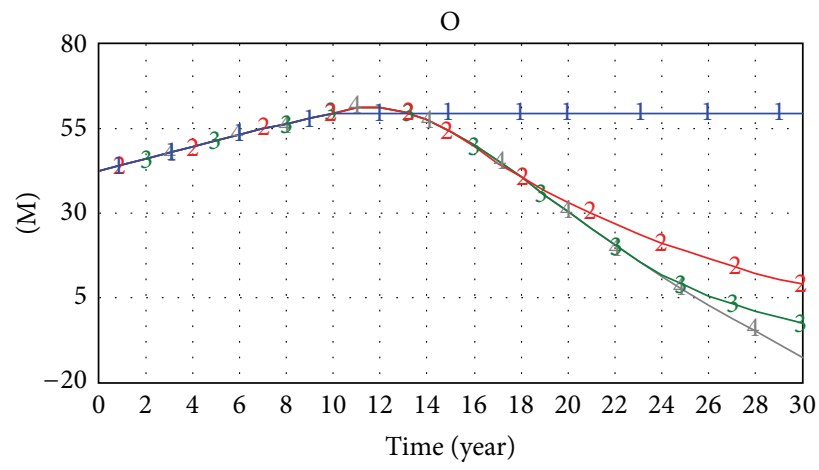

1 O: NOAd_N_full30_01_08_300_1000_10keep

2 O: NOAd_N_full30_01_08_300_1000_16keep

3 - O: NOAd_N_full30_01_08_300_1000_24keep

1 O: NOAd_N_full30_01_08_300_1000

(a) Annual profit

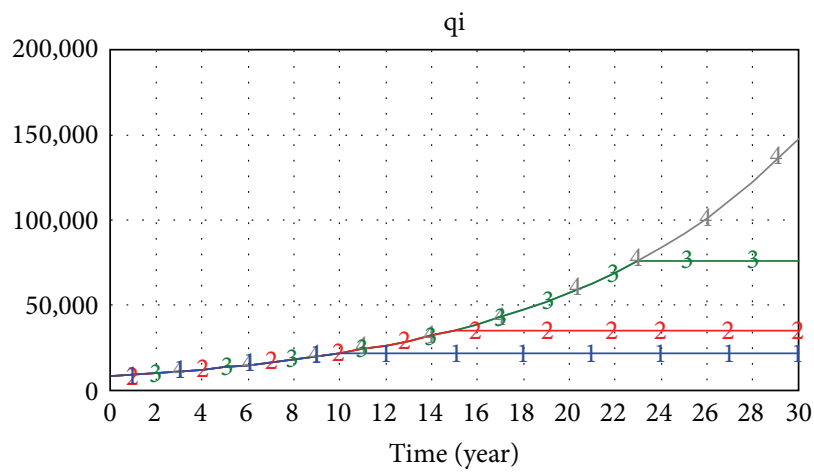

1 qi: NOAd_N_full30_01_08_300_1000_10keep

-2 qi: NOAd_N_full30_01_08_300_1000_16keep

3 - qi: NOAd_N_full30_01_08_300_1000_24keep

-4 qi: NOAd_N_full30_01_08_300_1000

(b) Annual sales volume

FIGURE 11: Contrast of profits when sales volumes stop growing at different years under brand dilution.

profit and revenue. In Figure 10, line 1 holds the critical point of LG consumer base. If the sales volume does not exceed it, the closer it is to this point, the higher profit the firm will gain. If the firm stops increasing sales volume earlier (as in Figure 10 line 3 shows), a big amount of potential profit is left unearned. Actually Proposition 2 has predicted the result.

Moreover, the firm will try to approach to the ideal boundary by reducing the price and bringing up the sales volume. However, as it is difficult to estimate the critical point close to line 1 , during this process, the sales volume might exceed the boundary and produce brand dilution, and consequently influence the LG consumer base, revenue, and profit.

Line 1 in Figure 11 shows the ideal situation. Once the brand is diluted, stopping sales volume growth at different years (lines 2-3) is little better than keeping sales volume growing (line 4) but still cannot prevent annual profit from continuous declining. In short, even if firms are aware of brand dilution, they could be in trouble when the critical point is hard to identify.

Obviously, the effects of brand purity are significant in the development journey of fashion firms. Once the brand is diluted, the firm's profits are continuously harmed, which underscores the necessity of identifying the critical point of brand dilution.

\subsection{Model Simulation of Sales Changing Trend}

5.2.1. Strategy 1: Increase Sales Volume Each Year. As the firm has inertia to increase sales volume, for example, by a certain 


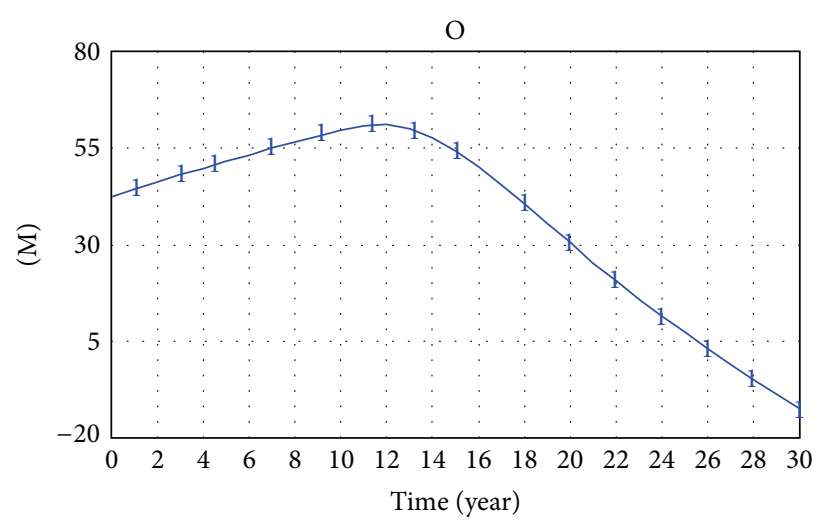

1 O: NOAd_N_full30_01_08_300_1000

(a) Profit

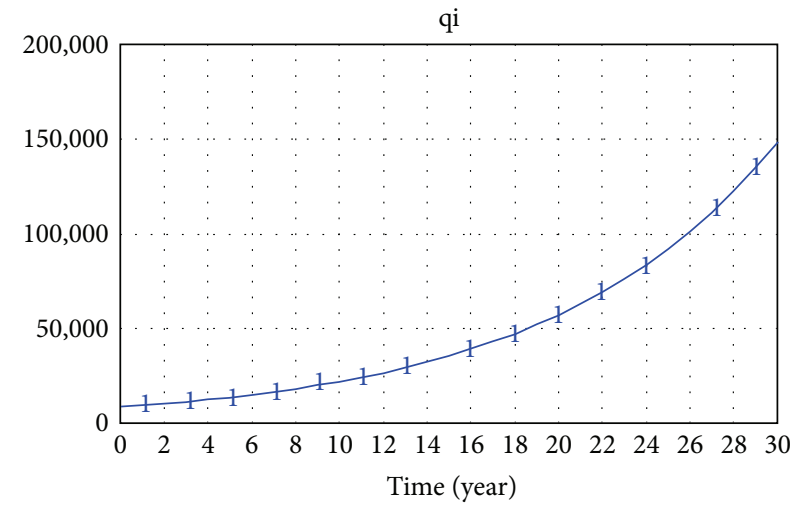

1 qi: NOAdN_full30_01_08_300_1000

(c) Sales volume

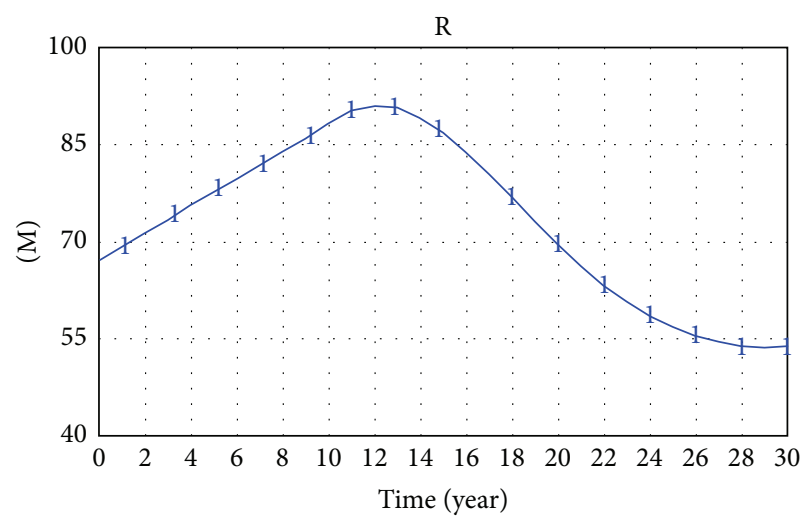

1 R: NOAd_N_full30_01_08_300_1000

(b) Revenue

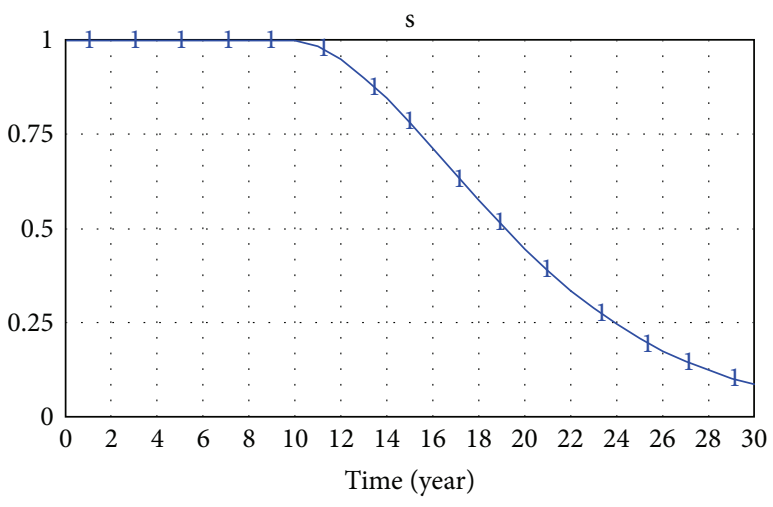

1 s: NOAd_N_full30_01_08_300_1000

(d) Brand purity

FIGURE 12: Simulation results under $10 \%$ of sales increasing rate.

proportion $(0<\theta<1)$, if the discussed initial sales volume is $q^{*}$, sales volume of year $i$ will be $q_{i}=q^{*}(1+\theta)^{i}$. What performance will the firm operate?

Example 9. Set the same parameters as Example 8. After nearly 10 years of growth, sales volume from LG is close to saturate the target market (critical point). If the firm still requests a $10 \%$ rising rate, then the majority of the new consumers will be FG. We conduct a simulation of 30-year development that consisted of profit, revenue, sales volume, and brand purity.

According to the results displayed in Figure 12, with the rising sales volume, the profit $(O)$ of the first 10 years is on the raise, and the brand purity keeps still. But as the sales to the LG tend to be saturated, FG join the consumer base and brings brand purity down quickly (Proposition 3 has also promised these properties), resulting in the continuous loss of high quality consumers of LG. Annual profit and the firm revenue decrease.

Market observations suggest that when firm grows with increasing sales volume and expanding market share, the firm performance is continuously strengthened. But after reaching a certain point, the situation begins to deteriorate, and revenue and profit go down as sales volume increases. Many fashion luxury brand firms have somewhat gone through similar stories as we mentioned at the beginning.

5.2.2. Strategy 2: Stop Increasing Sales When Profit Continuously Declines. The increase of sales volume does not necessarily suggest profit increase. It is not hard for luxury brand firms to control sales volume, when the brand is still perceived by consumers as luxury. In the following part, we discuss the situation where sales volume is kept fixed when the firm finds profit decreasing.

Example 10. The setting is the same as the setting in Example 8. Assume that the firm found profit declines with sales increase in the 12th year, and then it began keeping the sales volume fixed since the 16th year.

Line 1 in Figure 13 is the same as that in Figure 12. And line 2 is the simulation result of the new strategy. According to the simulation result, although the purpose of the new strategy is to mitigate the brand dilution caused by the increase of FG, the brand dilution (Figure 13(d)) does not slow down substantially. Proposition 4 has also predicted the results. The profit (Figure 13(a)) and the revenue (Figure 13(b)) continue 


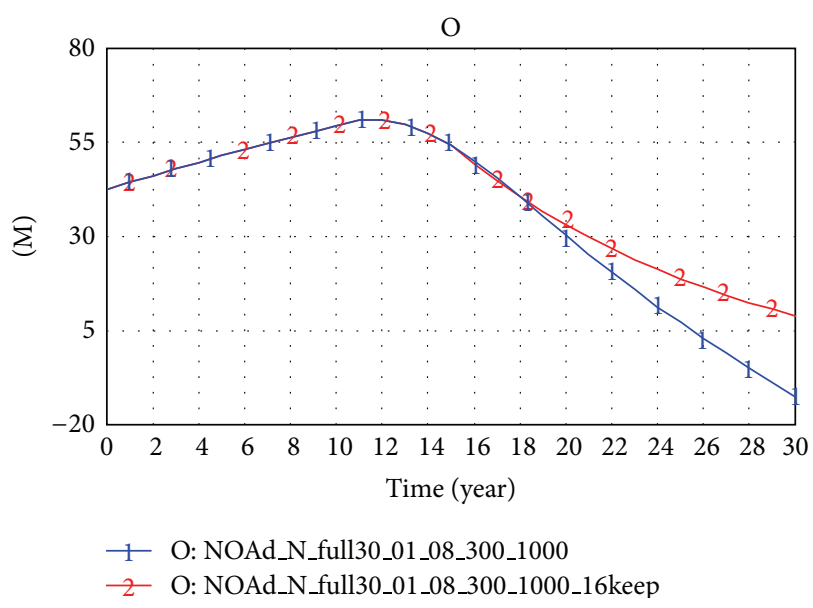

(a) Contrast of profit

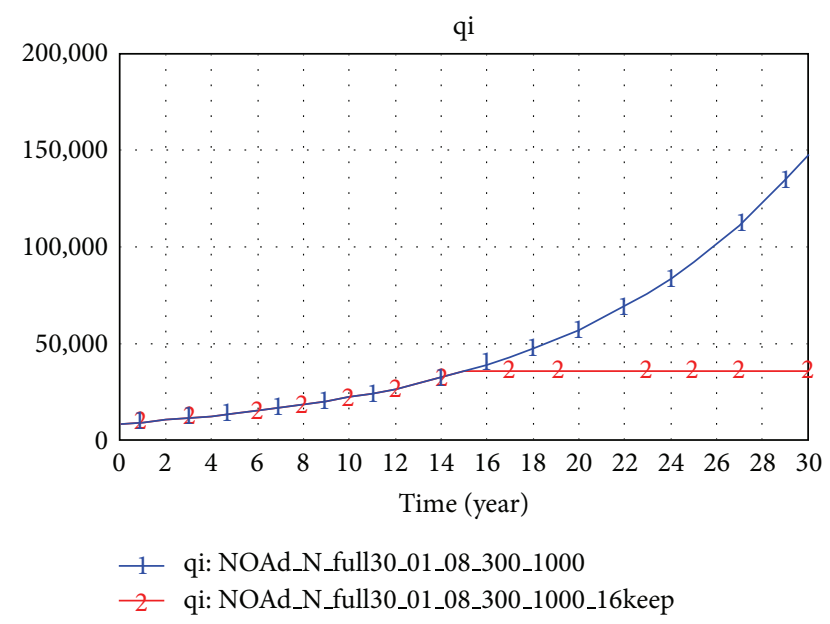

(c) Contrast of sales volume

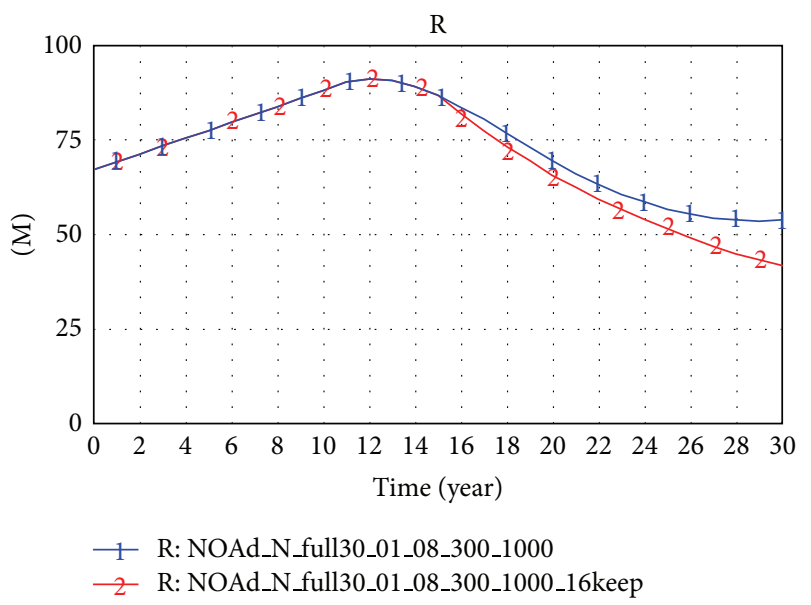

(b) Contrast of revenue

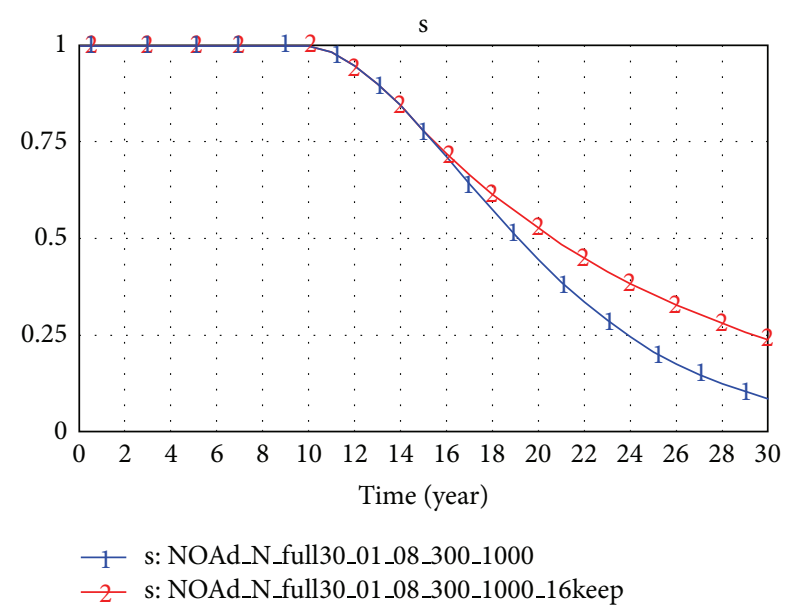

(d) Contrast of brand purity

FIgURE 13: Contrast of trend when stopping or continuing sales increase.

to decline at the same time, and the revenue performance is even worse than the profit. Keeping the sales volume the same (Figure 13(c)) is obviously not a good strategy either, because once brand is diluted, some LG consumers will leave continuously and only low-value FG consumers will come. While it is not viable to mitigate the brand dilution by stopping the sales volume growth, we test whether increasing the sales and lowering the product cost are helpful as another strategy.

\subsubsection{Strategy 3: Lower the Cost When Profit Continuously Declines}

Example 11. The setting is still the same with the setting as Example 8. Assume that the firm finds profit declines with sales increase in the 12th year and begins to cut down the cost in the 16th year. The variable cost is $10 \%$ lower each year, and the comparative cost is reduced to 60 (line 1), 30 (line 2), and 15 (line 3), respectively. We iterate the operation for fifty years.

According to the simulation result (Figure 14(a)), from the 16th year to the 30th year, cutting cost cannot prevent profit from rapid decline. After this, there is a rising trend of the profit during the 30th-to-50th-year period due to the cost cutting of line 2 and line 3 , but the brand purity is almost zero (Figure 14(b)). As variable cost goes down from 300 to 60, or even 15 , the perceived quality of commodities and services would be greatly discounted, which can no longer (may also seem unnecessary to) meet the LG's needs. The brand would be no longer for the LG group and degraded into a brand for the FG group since then.

5.2.4. Strategy 4: Reduce the Sales Volume Gradually When Profit Continuously Declines. To find a good reduction policy, we reduce the sales volume to different extents when profit continuously declines.

Example 12. The setting is still the same as the setting in Example 8. The firm starts to reduce the sales volume in the 16 th year after being aware of profit decline. Contrasting the results between that sales volume will stay less than and very close to the critical point $q^{*}$ (keep shrinking at $10 \%$ per year, 5 years in total, line 1 in Figure 15) and that sales volume will 


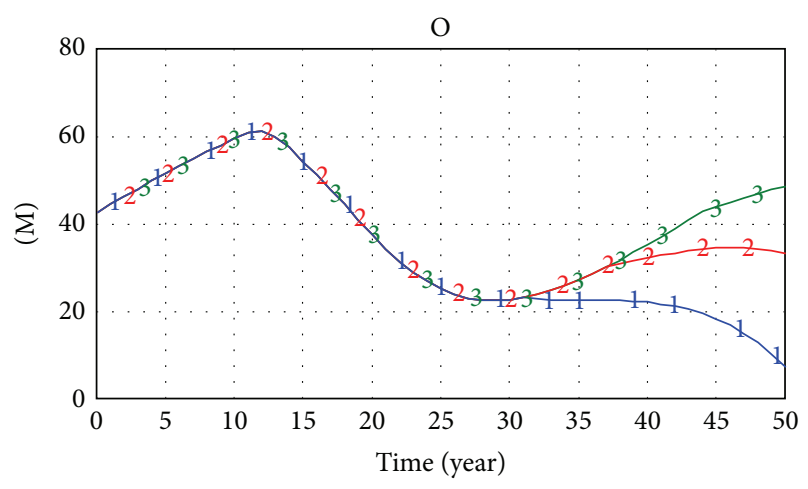

1 O: NOAd_N_full50_01_08_300_1000_15d60

2 O: NOAd_N_full50_01_08_300_1000_15d30

3 - O: NOAd_N_full50_01_08_300_1000_15d15

(a) Annual profit

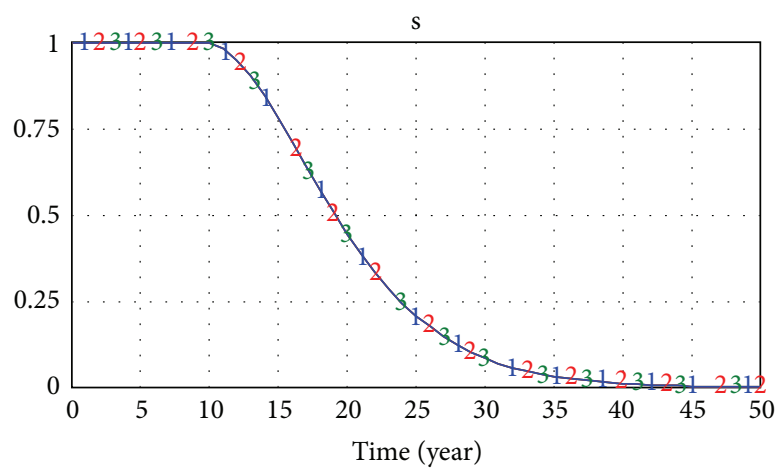

$1-$ s: NOAd_N_full50_01_08_300_1000_15d60
$2-$ s: NOAd_N_full50_01_08_300_1000_15d30
$-3-$ s: NOAd_N_full50_01_08_300_1000_15d15

(b) Brand dilution state

FIGURE 14: Contrast of profit when cut the cost and expand the sales volume.

be much less than $q^{*}$ (keep shrinking at $10 \%$ per year, 7 years in total, line 2 in Figure 15).

According to the simulation results, the two policies have their own pros and cons. A higher degree of shrinkage leads to faster recovery of brand dilution and greater short-term profit. However, in the long run, keeping the sales volume unchanged within and close to the critical point can increase profit to a higher level. This conclusion is supported by Proposition 5. In view of the possible change of the critical point in long term as well as the severe consequences of brand dilution, conservative policy as line 2 would be better, because it exerts effect more quickly and helps managers to establish confidence.

In conclusion, the last one among the strategies above will be practical and effective. Once brand dilution appears, it will harm the brand and undermine its performance significantly. The firm should immediately take action to improve the brand purity by limiting the sales to the target consumers, even though inevitably it will suffer profit decline. For fashion brands, avoiding brand dilution should be a long-term strategy. When the brand is diluted unintentionally, increasing price to block more FG consumers outside will help.

\section{Conclusion}

The brand dilution is widely discussed in the marketing and management literature and plays an important role in fashion brand management. We built a dynamic model for brand purity and performance based on two consumer groups (LG and FG) and fashion firms' actions. The model illustrates how brand dilution impacts fashion firm performance (revenue and profit) and draws the images that several famous fashion brands had experienced when brand diluting and degrading. Focusing on one of different processes of brand dilution as discussed in this paper, we introduce the brand purity concept and defined it with mathematical formula. It contributes to the literature of empirical studies on brand dilution. Seven propositions and related simulation results reflect and explain the real practices in fashion brand firms operations.
The simulations conducted in the context of fashion luxury brand industry provide interesting implications for researchers and practitioners: (1) brand dilution frequently emerges when firms are hard to discern the border between target and nontarget consumer groups and are impelled to keep increasing sales volumes. (2) Brand dilution leading to brand purity decline will harm a firm's revenue and profit, and the damage affects not only the brand but also the firm that owns the brand, unless actions are taken to prevent the brand from diluting. (3) Reducing the cost of the product can only help salvage the performance to some degree, but cannot completely prevent brand diluting. (4) Avoiding sell brand products to nontarget consumers helps increasing brand purity. Conservative policy that keeps only target consumers is suggested when the border between the two groups is vague.

Although the model provides useful implications for understanding the mechanism of brand purity and its impacts, our model has its limitation due to the static assumption of the critical point. Future research can further analyze the dynamical changing boundaries to refine the model for a longer time window. Moreover, advertising, an effective tool for improving brand image, can be introduced into the model to generate more implications.

\section{Appendices}

\section{A. Proof of Propositions}

Proof of Proposition 1. When $q_{i} \leq q^{*}$, only LG consumers purchase the product, but FG consumers do not; that is, $q_{L, i}>$ 0 and $q_{F, i}=0$. Therefore, we have brand purity $s_{i}=1$.

Proof of Proposition 2. $s_{i}=1$ implies $q_{i} \leq q^{*}$. From (1a) and (2a), the equation below can be derived, for $q_{i} \leq q^{*}$ :

$$
\begin{gathered}
R_{i}=p(\bar{q}) \bar{q} s_{i-1}+\int_{\bar{q}}^{q_{i}} p(q) s_{i-1} d q, \\
O_{i}=(p(\bar{q})-c) \bar{q} s_{i-1}+\int_{\bar{q}}^{q_{i}}(p(\bar{q})-c) s_{i-1} d q .
\end{gathered}
$$




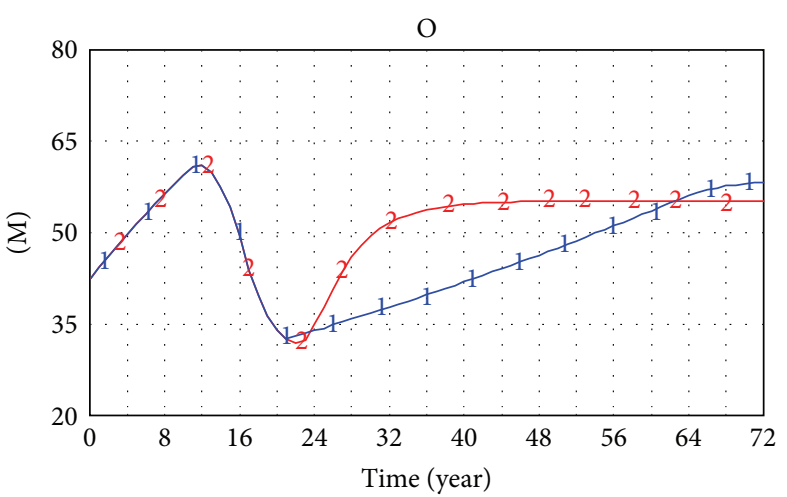

1 O: NOAd_N72_01_08_300_1000_16shrink5

2 O: NOAd_N72_01_08_300_1000_16shrink7

(a) Contrast of profit

qi

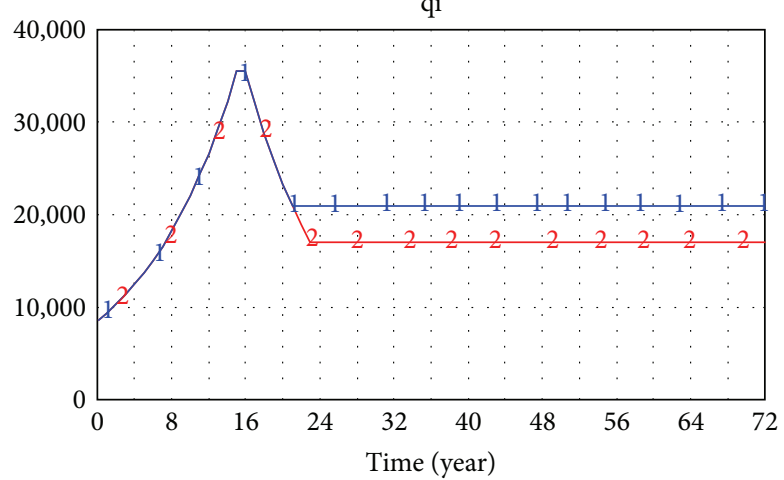

1 qi: NOAd_N72_01_08_300_1000_16shrink5

2 qi: NOAd_N72_01_08_300_1000_16shrink7

(c) Contrast of annual sales volume

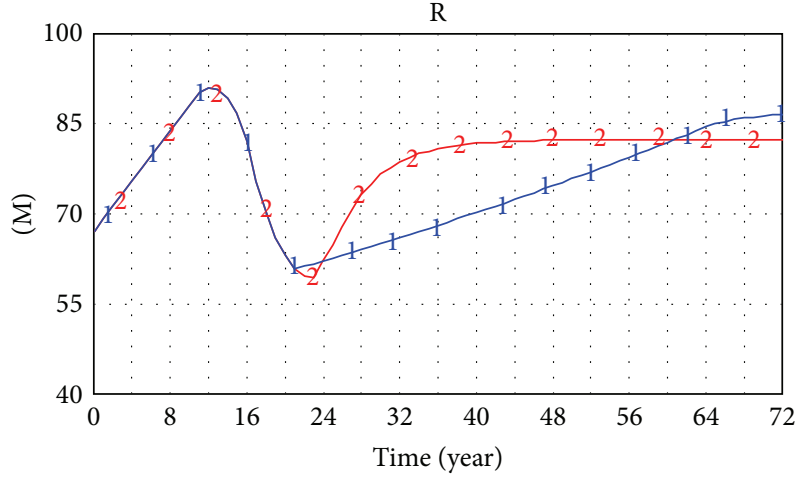

1 R: NOAd_N72_01_08_300_1000_16shrink5

2 R:NOAd_N72_01_08_300_1000_16shrink7

(b) Contrast of annual revenue

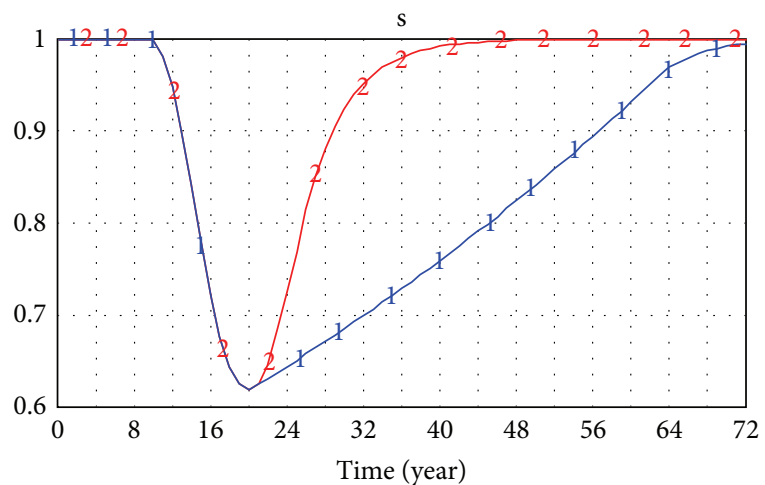

1 s: NOAd_N72_01_08_300_1000_16shrink5 2 s: NOAd_N72_01_08_300_1000_16shrink7

(d) Contrast of brand dilution state

FiguRE 15: Contrast of profit by different extent of contraction.

When $0<q_{i}<\bar{q}, \exists q_{i 1}, q_{i 2}$, and $0<q_{i 1}<q_{i 2}<\bar{q}$, that is,

$$
\begin{aligned}
& R\left(q_{i 1}\right)-R\left(q_{i 2}\right) \\
& \quad=p(\bar{q}) q_{i 1}-p(\bar{q}) q_{i 2} \\
& \quad=p(\bar{q})\left(q_{i 1}-q_{i 2}\right)<0, \quad \text { as } p(\bar{q})>0 ; \\
& O\left(q_{i 1}\right)-O\left(q_{i 2}\right) \\
& \quad=(p(\bar{q})-c) q_{i 1}-(p(\bar{q})-c) q_{i 2} \\
& \quad=(p(\bar{q})-c)\left(q_{i 1}-q_{i 2}\right)<0 \text { as } p(\bar{q})>p\left(q^{*}\right)>c .
\end{aligned}
$$

When $\bar{q}<q_{i}<q^{*}, \exists q_{i 1}, q_{i 2}$, and $\bar{q}<q_{i 1}<q_{i 2}<q^{*}$, that is,

$$
\begin{aligned}
& R\left(q_{i 1}\right)-R\left(q_{i 2}\right) \\
& =p(\bar{q}) \bar{q}+\int_{\bar{q}}^{q_{i 1}} p(q) d q \\
& \quad-\left(p(\bar{q}) \bar{q}+\int_{\bar{q}}^{q_{i 2}} p(q) d q\right)
\end{aligned}
$$

$$
\begin{aligned}
& =\int_{\bar{q}}^{q_{i 1}} p(q) d q-\left(\int_{\bar{q}}^{q_{i 1}} p(q) d q+\int_{q_{i 1}}^{q_{i 2}} p(q) d q\right) \\
& =-\int_{q_{i 1}}^{q_{i 2}} p(q) d q<0, \quad \text { as } p(q)>0 ;
\end{aligned}
$$$$
O\left(q_{i 1}\right)-O\left(q_{i 2}\right)
$$$$
=(p(\bar{q})-c) \bar{q}+\int_{\bar{q}}^{q_{i 1}}(p(q)-c) d q
$$$$
-\left((p(\bar{q})-c) \bar{q}+\int_{\bar{q}}^{q_{i 2}}(p(q)-c) d q\right)
$$$$
=\int_{\bar{q}}^{q_{i 1}}(p(q)-c) d q
$$$$
-\left(\int_{\bar{q}}^{q_{i 1}}(p(q)-c) d q+\int_{q_{i 1}}^{q_{i 2}}(p(q)-c) d q\right)
$$$$
=-\int_{q_{i 1}}^{q_{i 2}}(p(q)-c) d q<0,
$$

as $p(q)>0$ and $p(q) \geq p\left(q^{*}\right)>c$. 
Proof of Proposition 3. From (8), $s_{i}=\prod_{k=1}^{i}(\alpha+(1-\alpha) /$ $\left.\left(\prod_{j=1}^{k}\left(1+\theta_{j}\right)\right)\right)$, when $q_{0}=q^{*}$ and $s_{0}=1$; then

$$
\begin{gathered}
s_{1}=\alpha+\frac{1-\alpha}{1+\theta_{1}}<\alpha+\frac{1-\alpha}{1}=1, \quad \text { as } \theta_{1}>0, \\
\frac{s_{i+2}}{s_{i+1}}=\left(\alpha+\frac{1-\alpha}{\prod_{j=1}^{i+2}\left(1+\theta_{j}\right)}\right), \\
\frac{s_{i+1}}{s_{i}}=\left(\alpha+\frac{1-\alpha}{\prod_{j=1}^{i+1}\left(1+\theta_{j}\right)}\right) .
\end{gathered}
$$

that is

$$
\begin{aligned}
\left(\alpha+\frac{1-\alpha}{\prod_{j=1}^{i+2}\left(1+\theta_{j}\right)}\right) & <\left(\alpha+\frac{1-\alpha}{\prod_{j=1}^{i+1}\left(1+\theta_{j}\right)}\right) \\
& <\left(\alpha+\frac{1-\alpha}{1}\right)=1, \\
\frac{s_{i}}{s_{i-1}} & <\frac{s_{i-1}}{s_{i-2}}<1 .
\end{aligned}
$$

Proof of Proposition 4. Similar to Proof of Proposition 3

$$
\begin{aligned}
\frac{s_{i+2}}{s_{i+1}}= & \left(\alpha+\frac{1-\alpha}{\prod_{k=1}^{i+2}\left(1+\theta_{k}\right)}\right) \\
= & \left(\alpha+\frac{1-\alpha}{\prod_{k=1}^{H-1}\left(1+\theta_{k}\right) \prod_{k=H}^{i+2}\left(1+\theta_{k}\right)}\right), \\
& \text { as } \theta_{k}=0 \text { when } k \geq H, \theta_{k}>0 .
\end{aligned}
$$

When $k \in[1, H-1]$, then

$$
\frac{s_{i+2}}{s_{i+1}}=\left(\alpha+\frac{1-\alpha}{\prod_{k=1}^{H-1}\left(1+\theta_{k}\right)}\right)<1 .
$$

Similarly,

$$
\begin{gathered}
\frac{s_{i+1}}{s_{i}}=\left(\alpha+\frac{1-\alpha}{\prod_{k=1}^{H-1}\left(1+\theta_{k}\right)}\right)<1 . \\
\frac{s_{i+2}}{s_{i+1}}=\frac{s_{i+1}}{s_{i}}<1 .
\end{gathered}
$$

Proof of Proposition 5. If $q_{i}<q^{*} s_{i-1}$, then $q_{L, i}=q_{i}$. By (3), $s_{i}>s_{i-1}$. If $q^{*} s_{i-1} \leq q_{i}$, then $q_{L, i}=q^{*} s_{i-1}$. By (3), $s_{i}=\alpha s_{i-1}+$ $(1-\alpha)\left(q_{L, i} / q_{i}\right)=\alpha s_{i-1}+(1-\alpha)\left(q^{*} s_{i-1} / q_{i}\right)$, and $s_{i}>\alpha s_{i-1}+(1-$ $\alpha)\left(q^{*} s_{i-1} / q^{*}\right)=s_{i-1}$. If $s_{i} \geq s_{i-1}, \alpha s_{i-1}+(1-\alpha)\left(q^{*} s_{i-1} / q_{i}\right) \geq$ $s_{i-1}$, then $q_{i}<q^{*}$.
Proof of Proposition 6. From (3),

$$
\begin{aligned}
R_{i}- & R_{i-1} \\
= & p(\bar{q}) \bar{q}\left(s_{i-1}-s_{i-2}\right) \\
& +\int_{\bar{q}}^{q^{*}} p(q) d q\left(s_{i-1}-s_{i-2}\right) \\
& +\int_{q_{i-1}+\left(1-s_{i-2}\right) q^{*}}^{q_{i}+\left(1-s_{i-1}\right) q^{*}} p(q) d q, \\
R_{i}- & R_{i-1} \\
= & \left(p(\bar{q}) \bar{q}+\int_{\bar{q}}^{q^{*}} p(q) d q\right) \\
& \times\left(s_{i-1}-s_{i-2}\right)+\int_{q_{i-1}+\left(1-s_{i-2}\right) q^{*}}^{q_{i}+\left(1-s_{i-1}\right) q^{*}} p(q) d q \\
< & \left(p(\bar{q}) \bar{q}+\int_{\bar{q}}^{q^{*}} p(q) d q\right)\left(s_{i-1}-s_{i-2}\right) \\
& -p\left(q_{i}+\left(1-s_{i-2}\right) q^{*}\right) q^{*}\left(s_{i-1}-s_{i-2}\right), \\
R_{i}- & R_{i-1} \\
< & \left(p(\bar{q}) \bar{q}+\int_{\bar{q}}^{q^{*}} p(q) d q-p\left(q_{i}+\left(1-s_{i-1}\right) q^{*}\right) q^{*}\right) \\
& \times\left(s_{i-1}-s_{i-2}\right) \\
< & \left(p\left(q^{*}\right) q^{*}-p\left(q_{i}+\left(1-s_{i-2}\right) q^{*}\right) q^{*}\right) \\
& \times\left(s_{i-1}-s_{i-2}\right) .
\end{aligned}
$$

Apparently, the mathematical expression is below zero, since

$$
\left(p\left(q^{*}\right) q^{*}-p\left(q_{i}+\left(1-s_{i-2}\right) q^{*}\right) q^{*}\right)>0,
$$

where $d p / d q<0, q^{*}<q_{i}+\left(1-s_{i-2}\right) q^{*}$. You know $s_{0}=1$, $s_{1}<1$; then $q_{1}>q^{*} ; q_{2} \geq q_{1}$; so $q^{*}<q_{i}$ when $i \geq 2$, and $s_{i-2} \leq 1$.

And from Proposition $4, s_{i-1}-s_{i-2}<0$. So $R_{i}-R_{i-1}<0$. Similarly,

$$
\begin{aligned}
O_{i}-O_{i-1}= & (p(\bar{q})-c) \bar{q}\left(s_{i-1}-s_{i-2}\right) \\
& +\int_{\bar{q}}^{q^{*}}(p(q)-c) d q\left(s_{i-1}-s_{i-2}\right) \\
& +\int_{q_{i-1}+\left(1-s_{i-2}\right) q^{*}}^{q_{i}+\left(1-s_{i-1}\right) q^{*}}(p(q)-c) d q \\
= & p(\bar{q}) \bar{q}\left(s_{i-1}-s_{i-2}\right) \\
& +\int_{\bar{q}}^{q^{*}} p(q) d q\left(s_{i-1}-s_{i-2}\right) \\
& +\int_{q_{i-1}+\left(1-s_{i-2}\right) q^{*}}^{q_{i}+\left(1-s_{i-1}\right) q^{*}} p(q) d q \\
= & R_{i}-R_{i-1}<0 .
\end{aligned}
$$




\section{B. Example of Mathematic Expression in SD Model with Linear Sale Curve}

Consider the following:
(01) $\mathrm{a}=0.8$
(02) $\mathrm{b}=1400$
(03) $\mathrm{C}=100000$
(04) $\mathrm{cc}=300$
(05) FINAL TIME $=30$
Units: Year
(06) INITIAL TIME $=0$
Units: Year

(07) $\mathrm{k}=0.02$

(08) $\mathrm{O}=(\mathrm{b}-\mathrm{k} * \mathrm{q} /-\mathrm{cc}) * \mathrm{q} / * \operatorname{DELAY} 1(\mathrm{~s}, 1)+(1 / 2) *(2 *$ $\left.\mathrm{b}-\mathrm{k} *\left(" \mathrm{q} * "+\mathrm{q}^{\prime}\right)-2 * \mathrm{cc}\right) *(\mathrm{q} * "-\mathrm{q} \prime) * \operatorname{DELAY} 1(\mathrm{~s}, 1)+$ $(1 / 2) *(2 * \mathrm{~b}-\mathrm{k} *(\mathrm{qi}+(1-\operatorname{DELAY} 1(\mathrm{~s}, 1)) * \mathrm{q} * "+\mathrm{q} * ")$ $-2 * \mathrm{cc}) *(\mathrm{qi}+(1-\operatorname{DELAY} 1(\mathrm{~s}, 1)) * \mathrm{q} *$ * $-\mathrm{q} * ")-\mathrm{C}$

(09) $\mathrm{q}$ ' $=1000$

(10) $" \mathrm{q} * "=20000$

(11) $\mathrm{qi}=\operatorname{INTEG}(\mathrm{qi} * 0.1,7710.87)$

(12) $\mathrm{qL}=" \mathrm{q} * " * \operatorname{DELAY} 1(\mathrm{~s}, 1)$

(13) $\mathrm{R}=\left(\mathrm{b}-\mathrm{k} * \mathrm{q}^{\prime}\right) * \mathrm{q} \prime * \operatorname{DELAY} 1(\mathrm{~s}, 1)+(1 / 2) *(2 *$ $\mathrm{b}-\mathrm{k} *(" \mathrm{q} * "+\mathrm{q} /)) *(" \mathrm{q} * "-\mathrm{q} /) * \operatorname{DELAY} 1(\mathrm{~s}, 1)+$ $(1 / 2) *(2 * \mathrm{~b}-\mathrm{k} *(\mathrm{qi}+(1-\operatorname{DELAY} 1(\mathrm{~s}, 1)) * \mathrm{q} *$ " + "q * "))*(qi + (1 - DELAY1 $(\mathrm{s}, 1)) *$ "q * " - "q * ")

(14) $\mathrm{s}=\operatorname{ACTIVE}$ INITIAL $(\mathrm{a} * \operatorname{DELAY} 1 \mathrm{I}(\mathrm{s}, 1,1)+(1-\mathrm{a}) *$ IF THEN ELSE (qi > qL, qL/qi, 1), 1).

\section{Example of Mathematic Expression in SD Model with Convex Sale Curve in Section 3}

Consider the following:

(01) $\mathrm{a}=0.8$

(02) $\mathrm{C}=20000000$

(03) $\mathrm{cc}=300$

(06) $\mathrm{k}=20000000$

(07) $\mathrm{O}=(\mathrm{k} /-\mathrm{cc}) * \mathrm{q} / * \operatorname{DELAY} 1(\mathrm{~s}, 1)+\mathrm{LN}(\mathrm{q} *) * \mathrm{k} *$ $\operatorname{DELAY} 1(\mathrm{~s}, 1)-\mathrm{cc} * " \mathrm{q} *$ * $* \operatorname{DELAY} 1(\mathrm{~s}, 1)-\left(\mathrm{LN}\left(\mathrm{q}^{\prime}\right) *\right.$ $\mathrm{k} * \operatorname{DELAY} 1(\mathrm{~s}, 1)-\mathrm{cc} * \mathrm{q} / * \operatorname{DELAY} 1(\mathrm{~s}, 1))+\mathrm{LN}(\mathrm{qi}+$ $(1-\operatorname{DELAY} 1(\mathrm{~s}, 1)) *$ "q $*$ ") $* \mathrm{k}-\mathrm{cc} *(\mathrm{qi}+(1-$ $\operatorname{DELAY} 1(\mathrm{~s}, 1)) * \mathrm{q} *$ ") $-(\mathrm{LN}(" \mathrm{q} * ") * \mathrm{k}-\mathrm{cc} * " \mathrm{q} *$ ") $-\mathrm{C}$

(08) $\mathrm{q}$ ' $=1000$

(09) $" \mathrm{q} * "=20000$

(10) $\mathrm{qi}=\operatorname{INTEG}(\mathrm{qi} * 0.1,7710.87)$

(11) $\mathrm{qL}=$ "q * " DELAY1 $(\mathrm{s}, 1)$

(12) $\mathrm{R}=\mathrm{k} / \mathrm{q}$ ' $* \mathrm{q}$ ' $* \operatorname{DELAY} 1(\mathrm{~s}, 1)+\mathrm{LN}(" \mathrm{q} *$ ") $* \mathrm{k} *$ $\operatorname{DELAY} 1(\mathrm{~s}, 1)-\mathrm{LN}(\mathrm{q} \prime) * \mathrm{k} * \operatorname{DELAY} 1(\mathrm{~s}, 1)+\mathrm{LN}(\mathrm{qi}+$ $(1-\operatorname{DELAY} 1(\mathrm{~s}, 1)) * \mathrm{q} * ") * \mathrm{k}-\mathrm{LN}(" \mathrm{q} * ") * \mathrm{k}$
(13) $\mathrm{s}=\operatorname{ACTIVE~INITIAL~}(\mathrm{a} * \operatorname{DELAY} 1 \mathrm{I}(\mathrm{s}, 1,1)+(1-\mathrm{a}) *$ IF THEN ELSE (qi > qL, qL/qi, 1), 1)

(15) TIME STEP = 1

Units: Year [0, ?].

\section{Acknowledgments}

The authors sincerely thank the anonymous reviewers for their constructive comments on this paper and thank Xuefei Zhao, Hang Guan, Lu Hua, Jinling Yang, Qi Li, Wenjing Yang, and Wanshan Li for their help in preparing this paper. This paper is partially supported by Tongshan Fund and "985 project" of Sun Yat-sen University.

\section{References}

[1] D. A. Aaker and K. L. Keller, "Consumer evaluations of brand extensions," The Journal of Marketing, vol. 54, pp. 27-41, 1990.

[2] W. Amaldoss and S. Jain, "Pricing of conspicuous goods: a competitive analysis of social effects," Journal of Marketing Research, vol. 42, no. 1, pp. 30-42, 2005.

[3] W. Amaldoss and S. Jain, "Conspicuous consumption and sophisticated thinking," Management Science, vol. 51, no. 10, pp. 1449-1466, 2005.

[4] R. W. Belk, "Possessions and the extended self," Journal of Consumer Research, vol. 15, pp. 139-168, 1988.

[5] E. L. Grubb and H. L. Grathwohl, "Consumer self-concept, symbolism and market behavior: a theoretical approach," The Journal of Marketing, vol. 31, pp. 22-27, 1967.

[6] H. Leibenstein, "Bandwagon, snob, and Veblen effects in the theory of consumers' demand," The Quarterly Journal of Economics, vol. 64, pp. 183-207, 1950.

[7] J. H. Zheng, C. H. Chiu, and T. M. Choi, "Optimal advertising and pricing strategies for luxury fashion brands with social influences," IEEE Transactions on Systems, Man and Cybernetics Part A, vol. 42, pp. 827-837, 2012.

[8] M. Chevalier and G. Mazzalovo, Luxury Brand Management: A World of Privilege, Wiley, 2012.

[9] K. Jerath, S. Netessine, and S. K. Veeraraghavan, "Revenue management with strategic customers: last-minute selling and opaque selling," Management Science, vol. 56, no. 3, pp. 430$448,2010$.

[10] C. M. Moore and G. Birtwistle, "The Burberry business model: creating an international luxury fashion brand," International Journal of Retail \& Distribution Management, vol. 32, pp. 412422, 2004.

[11] P. M. Kort, J. P. Caulkins, R. F. Hartl, and G. Feichtinger, "Brand image and brand dilution in the fashion industry," Automatica, vol. 42, no. 8, pp. 1363-1370, 2006.

[12] B. Loken and D. R. John, "Diluting brand beliefs: when do brand extensions have a negative impact?" The Journal of Marketing, pp. 71-84, 1993.

[13] E. Martínez and L. De Chernatony, "The effect of brand extension strategies upon brand image," Journal of Consumer Marketing, vol. 21, no. 1, pp. 39-50, 2004.

[14] C. Pullig, C. J. Simmons, and R. G. Netemeyer, "Brand dilution: when do new brands hurt existing brands?" Journal of Marketing, vol. 70, no. 2, pp. 52-66, 2006. 
[15] S. M. Broniarczyk and J. W. Alba, "The importance of the brand in brand extension," Journal of Marketing Research, vol. 31, pp. 214-228, 1994.

[16] S. Spiggle, H. T. Nguyen, and M. Caravella, "More than fit: brand extension authenticity," Journal of Marketing Research, vol. 49, pp. 967-983, 2012.

[17] K. Srivastava and N. K. Sharma, "Consumer attitude towards brand-extension incongruity: the moderating role of need for cognition and need for change," Journal of Marketing Management, vol. 28, pp. 652-675, 2012.

[18] T. M. Choi, N. Liu, S. C. Liu, J. Mak, and Y. T. To, "Fast fashion brand extensions: an empirical study of consumer preferences," Journal of Brand Management, vol. 17, no. 7, pp. 472-487, 2010.

[19] T. M. Choi, S. C. Liu, C. S. Tang, and Y. Yu, "A cross-cluster and cross-region analysis of fashion brand extensions," Journal of the Textile Institute, vol. 102, pp. 890-904, 2011.

[20] S. Kim and H. Chung, "The impacts of perceived fit, brand familiarity, and status consciousness on fashion brand extension evaluation," International Journal of Fashion Design, Technology and Education, 2012.

[21] Y. J. Han, J. C. Nunes, and X. Drèze, "Signaling status with luxury goods: the role of brand prominence," Journal of Marketing, vol. 74, no. 4, pp. 15-30, 2010.

[22] M. B. Brewer, "The social self: on being the same and different at the same time," Personality and Social Psychology Bulletin, vol. 17, pp. 475-482, 1991.

[23] K. T. Tian, W. O. Bearden, and G. L. Hunter, "Consumers' need for uniqueness: scale development and validation," Journal of Consumer Research, vol. 28, no. 1, pp. 50-66, 2001.

[24] M. Husic and M. Cicic, "Luxury consumption factors," Journal of Fashion Marketing and Management, vol. 13, no. 2, pp. 231$245,2009$.

[25] A. Shipman, "Lauding the leisure class: symbolic content and conspicuous consumption," Review of Social Economy, vol. 62, no. 3, pp. 277-289, 2004.

[26] J. H. Zheng, B. Shen, P. S. Chow, and C. H. Chiu, "The impact of the strategic advertising on luxury fashion brands with social influences," Mathematical Problems in Engineering, 2013.

[27] N. A. Morgan and L. L. Rego, "Brand portfolio strategy and firm performance," Journal of Marketing, vol. 73, no. 1, pp. 59-74, 2009.

[28] R. J. Slotegraaf and K. Pauwels, "The impact of brand equity and innovation on the long-term effectiveness of promotions," Journal of Marketing Research, vol. 45, no. 3, pp. 293-306, 2008.

[29] S. Jørgensen and A. D. Liddo, "Design imitation in the fashion industry," Advances in Dynamic Game Theory, vol. 9, pp. 569586, 2007.

[30] K. C. Lau and I. Phau, "Extending symbolic brands using their personality: examining antecedents and implications towards brand image fit and brand dilution," Psychology and Marketing, vol. 24, no. 5, pp. 421-444, 2007.

[31] J. M. Magid, A. D. Cox, and D. S. Cox, "Quantifying brand image: empirical evidence of trademark dilution," American Business Law Journal, vol. 43, no. 1, pp. 1-42, 2006.

[32] R. N. Bolton, "The relationship between market characteristics and promotional price elasticities," Marketing Science, vol. 8, pp. 153-169, 1989. 


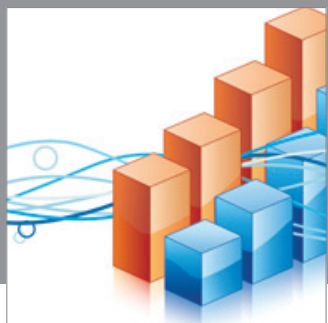

Advances in

Operations Research

mansans

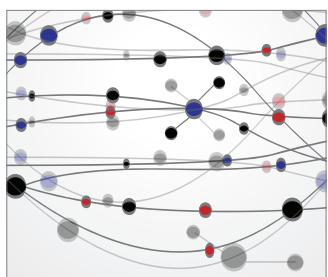

The Scientific World Journal
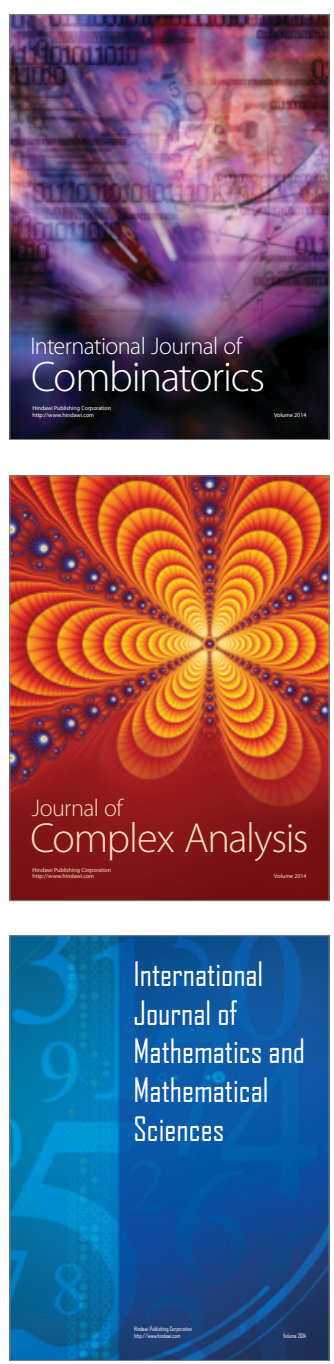
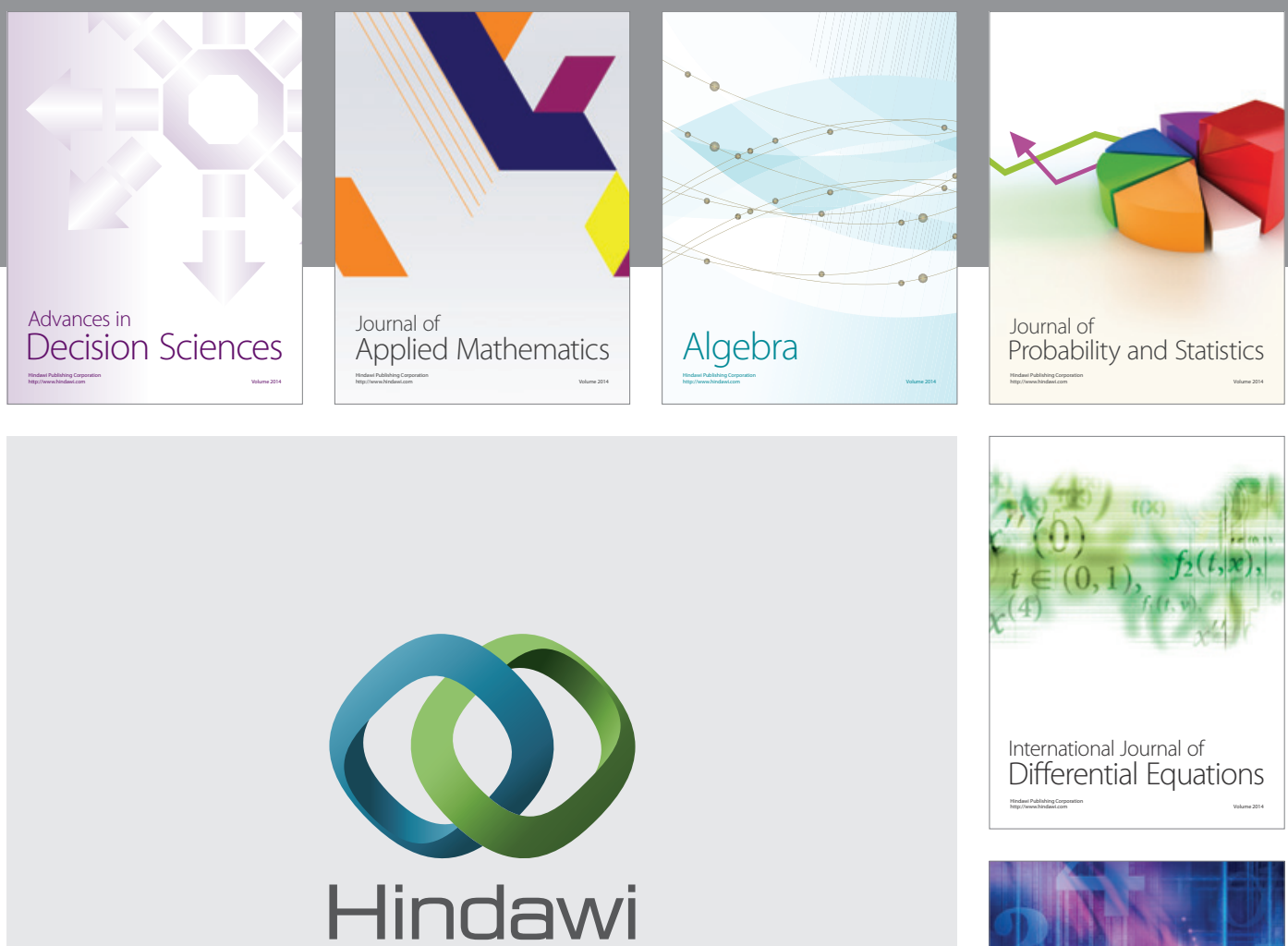

Submit your manuscripts at http://www.hindawi.com
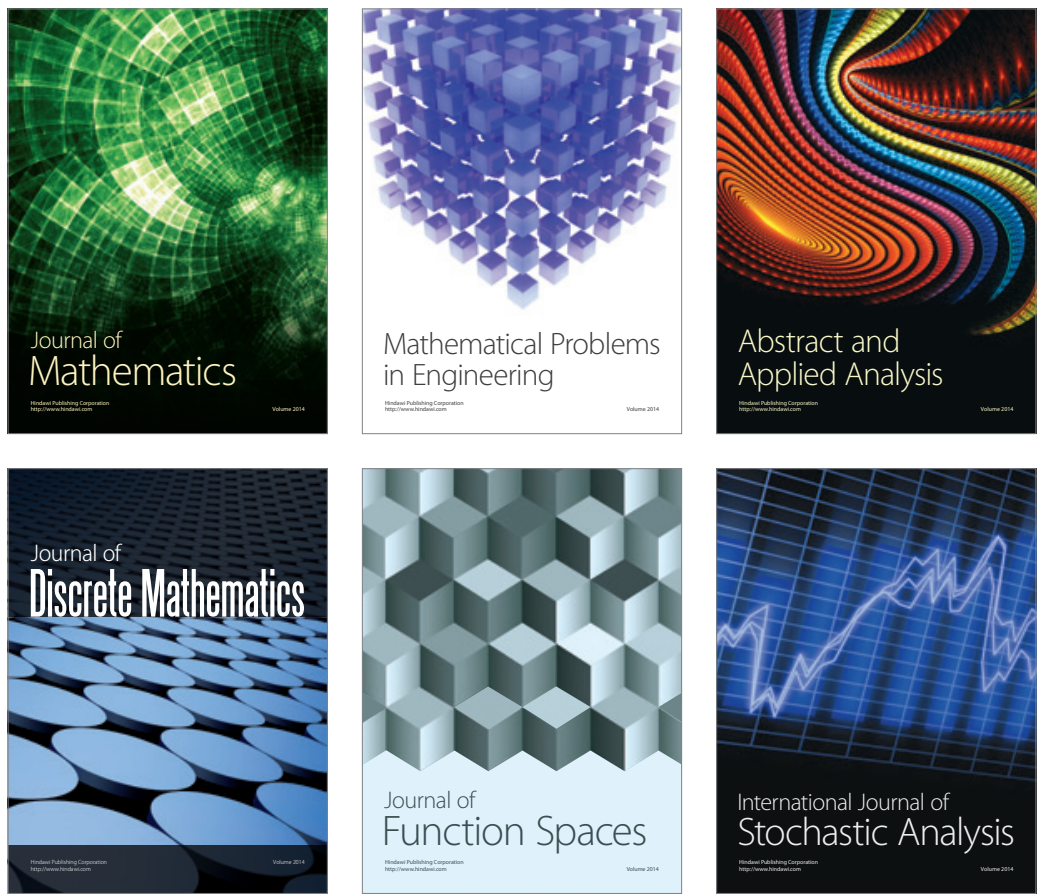

Journal of

Function Spaces

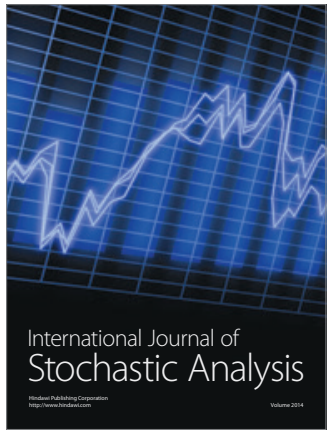

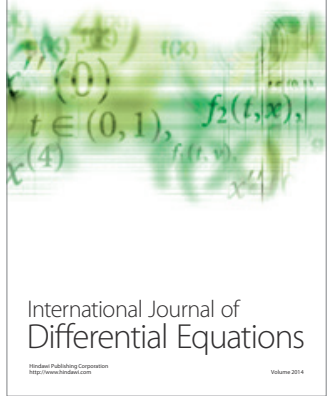
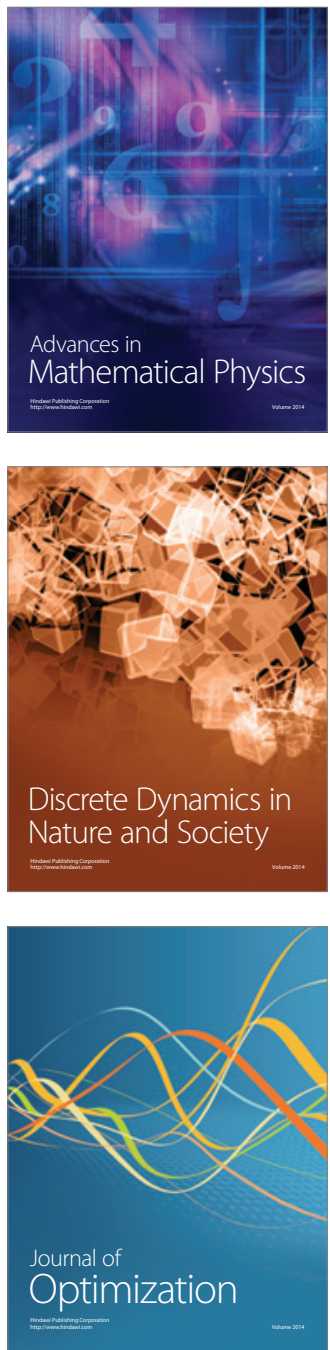